\title{
FIGURAS HUMANAS EN LAS MEJILLAS DE LAS URNAS SANTAMARIANAS (PRIMERA PARTE). ESTUDIO DE LOS CASOS PUBLICADOS A LA FECHA
}

\author{
HUMAN FIGURES ON SANTA MARÍA URNS (PART I). A STUDY OF CASES \\ PUBLISHED TO DATE
}

Javier Nastria Natasha Mirosnikove Agustina Longoc \& Sofía Gandin ${ }^{\circ}$

Se compila el conjunto de casos de representaciones humanas pintadas en las mejillas de las urnas santamarianas, desde fines del siglo xix hasta la actualidad. Se completa parte de la información no consignada en las publicaciones, como de vistas de las piezas. Se analiza la cuestión de la cronología de estas urnas fase iv, como así también se desarrollan ideas acerca de la función que las imágenes de personas pudieron tener en el seno de los antiguos sistemas de representaciones calchaquíes del actual Noroeste Argentino.

Palabras clave: Santa María, Urnas funerarias, Iconografía, Figura humana.

This paper compiles the set of studies about human depictions painted on the cheeks of Santa Maria urns from the late 19th century to the present. Information not consigned in previous researches is added and pictures are included. Chronology of the urns from fase IV is analyzed and ideas about the function that human figures could have portrayed within representation systems of the ancient Calchaqui people from Northwest Argentina aredeveloped.

Keywords: Santa María, Funerary urns, Iconography, Human figure.
Las representaciones humanas de cuerpo completo pintadas en la superficie exterior de las urnas santamarianas (fig. 1) proporcionan una vía de acceso al modo en el que probablemente eran vistos algunos de los individuos pertenecientes a categorías sociales específicas durante el Período Intermedio Tardío en los Valles Calchaquíes (fig. 2). Tanto la apariencia externa de los personajes representados como los contrastes evidentes entre las distintas formas que exhiben los mismos son datos a partir de los cuales es posible profundizar en el conocimiento de la estructura y organización social propias de las antiguas poblaciones de la región. Pues en el vestido y parafernalia asociada se expresan tanto la función como el estatus de los individuos. De esta manera la discusión en profundidad de las distintas alternativas interpretativas que se derivan de la observación de las características de las figuras se revela como una vía interesante de aproximación a las antiguas concepciones

\footnotetext{
A Javier Nastri. Universidad Maimónides-Conicet, CebBad, Depto. de CC. NA. y Antropológicas, Fundación Azara. Hidalgo 775, CABA, Argentina. Email: nastri.javier@maimonides.edu

B Natasha Mirosnikov. Pasante de investigación en la Fundación Azara. Hidalgo 775, CABA, Argentina. Email: natashamiros@hotmail.com

C Agustina Longo. Becaria doctoral de la Universidad Nacional de La Plata, Facultad de Ciencias Naturales y Museo. 122 y 60. La Plata, Argentina. Email: agustinalongo@fcnym.unlp.edu.ar

D Sofía Gandini. Becaria doctoral de la Agencia Nacional de Promoción Científica y Tecnológica en la Universidad Maimónides, CEBBAD, Depto. de Cs. Nat. y Antropológicas. Hidalgo 775, CABA, Argentina. Email: sofiagandini@gmail.com
} 


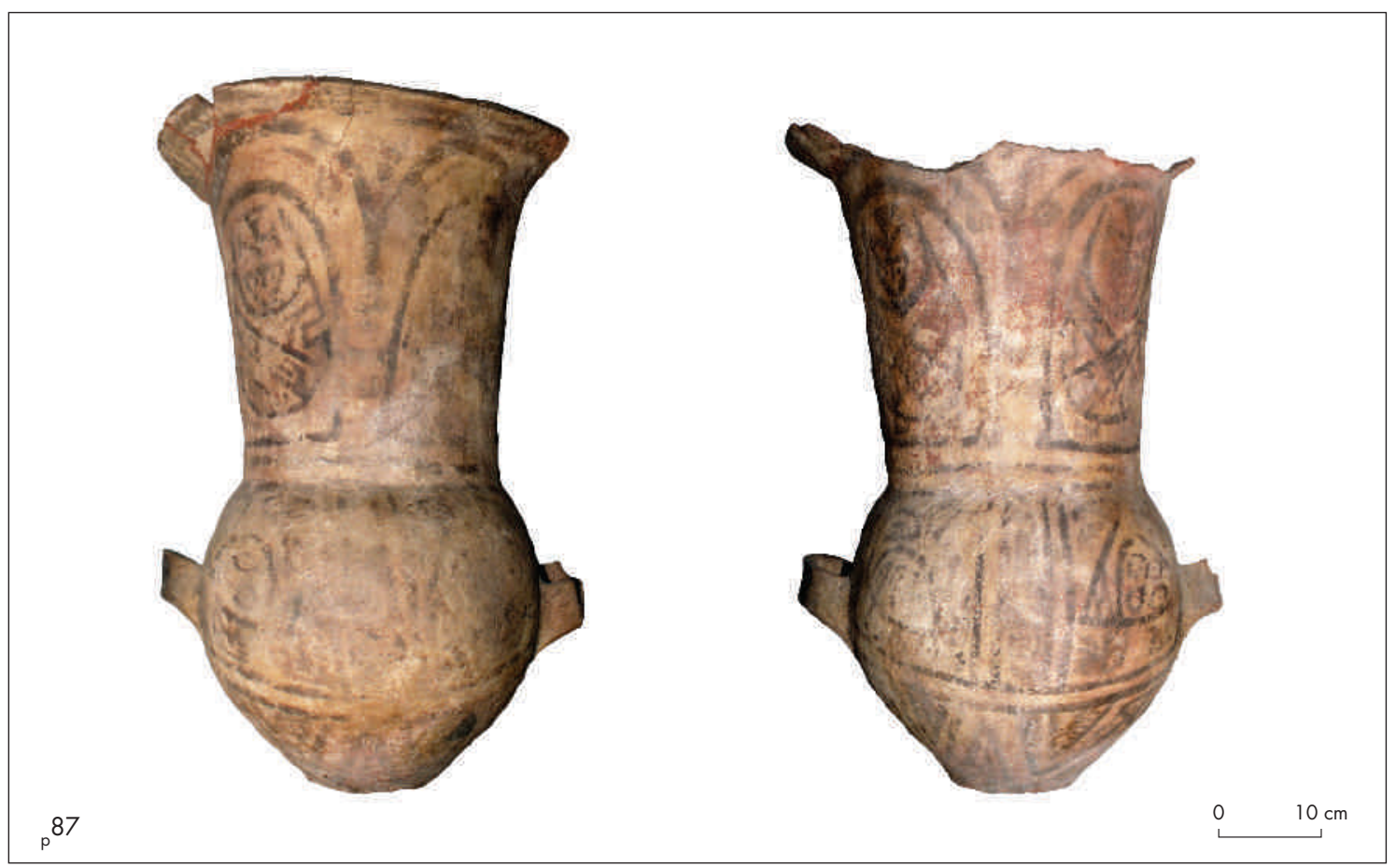

Figura 1. Urna santamariana ( 87 ) con figuras humanas pintadas en el cuello. Figure 1. Santa María urn ( 87 ) with human figures painted onto the neck.

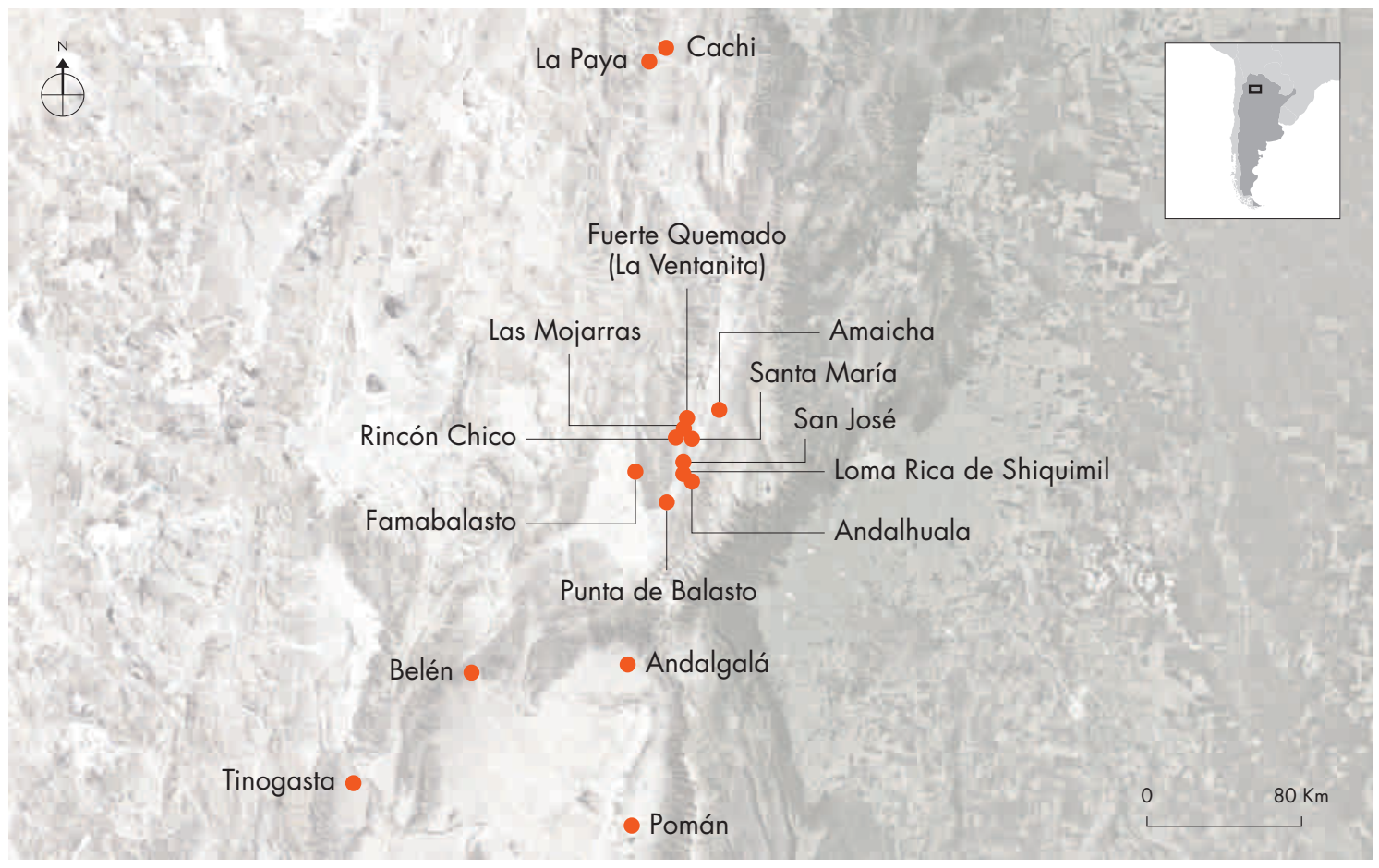

Figura 2. Área de estudio con ubicación de las localidades arqueológicas mencionadas en el texto. Figure 2. Area of study showing the location of archeological localilties mentioned in the text. 


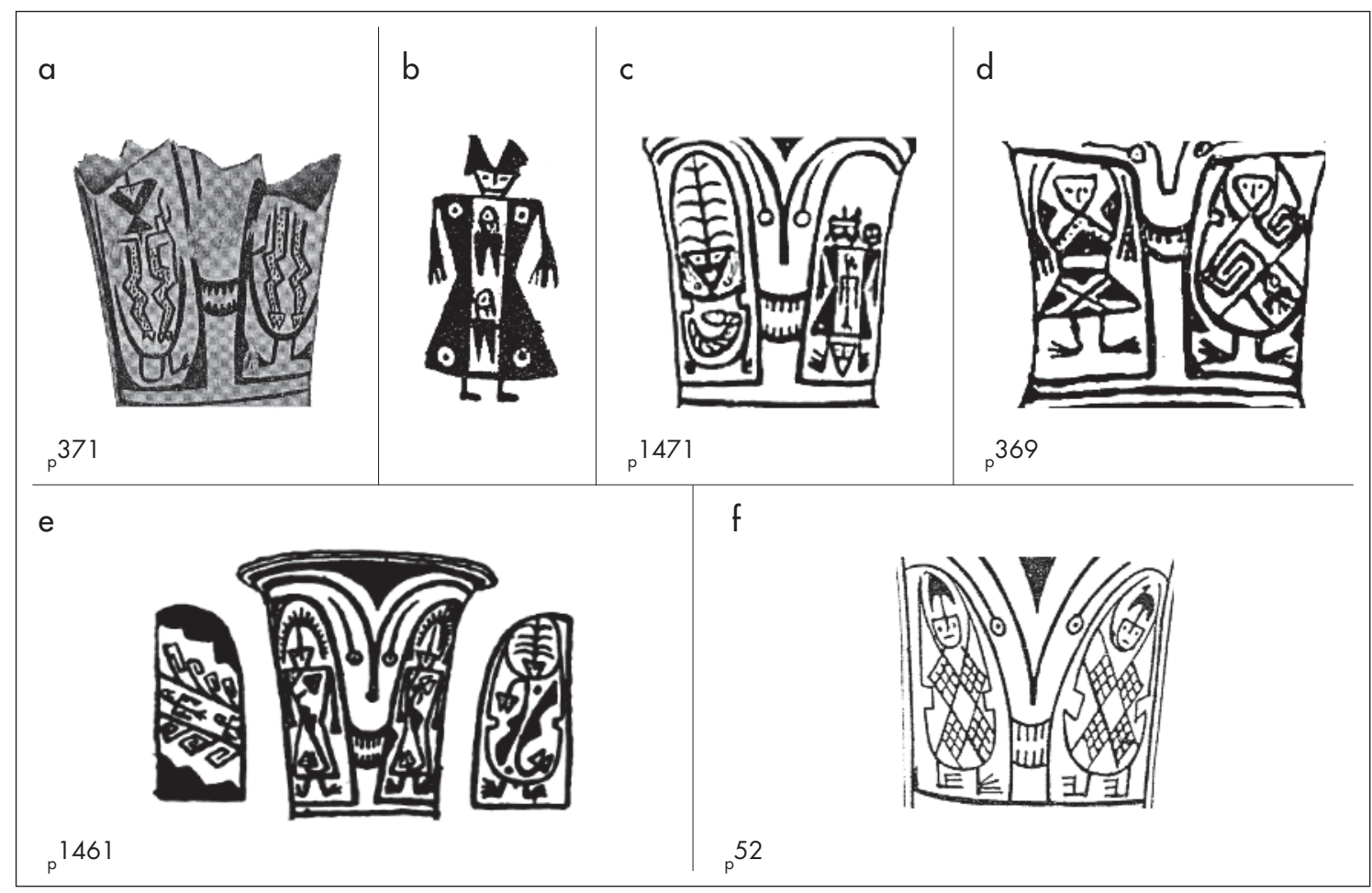

Figura 3: a) detalle de las representaciones en el cuello de 371 según Liberani y Hernández (1951); b) representación humana incluida en la iconografía de una urna de la colección de Max Schmidt (tomado de Ambrosetti 1898: 56); c) detalle de las representaciones en el cuello de 1471 según Quiroga (1901: 143, 1992: 328); d) detalle de las representaciones en el cuello de 369 según Ambrosetti (1899: 175); e) iconografía del cuello de 1461 según Quiroga (1992: 329); f) detalle de las representaciones en el cuello de 52 según Lafone Quevedo (1908: 345). Figure 3: a) detail of representaions on the neck of 371 as per Liberani and Hernández (1951); b human figure in the iconography of an urn from the Max Schmidt collection (taken by Ambrosetti 1898: 56); c) detail of representations on the neck of 1471 as per Quiroga (1901: 143, 1992: 328); d) detail of representations on the neck of 369 as per Ambrosetti (1899: 175); e) iconography on the neck of 1461 as per Quiroga (1992: 329); f) detail of representations on the neck of 52 as per Lafone Quevedo (1908: 345).

sobre la humanidad y los roles sociales durante el período Intermedio Tardío en los Valles Calchaquíes. El objetivo del presente trabajo es la compilación del conjunto de registros dispersos en los textos dados a conocer desde fines del siglo Xix, la reconstrucción de información contextual no consignada en las publicaciones, así como también el enriquecimiento de los registros con la información correspondiente a aquellas normas de las piezas (anverso o reverso) no incluidas en los artículos o capítulos de libros en los cuales fueron originalmente presentadas a la comunidad científica. Al mismo tiempo, se ensaya una primera clasificación de las variantes de los motivos, la cual será enriquecida próximamente con los datos de una siguiente contribución dedicada a casos hasta el momento totalmente inéditos, la adición de los cuales implicará una duplicación del tamaño de la muestra.

\section{RECONOCIMIENTO DE LAS REPRESENTACIONES HUMANAS}

Ya en la primera expedición arqueológica que inaugura la tradición de trabajos de investigación en los Valles Calchaquíes -efectuada a la Loma Rica de Shiquimil en los años 1876 y 1877 (Nastri 2003)- se exhumó una urna santamariana con representaciones humanas pintadas en el cuello (fig. 3a). Los autores indicaron que, tanto la pieza en cuestión como otras similares descubiertas en el mismo y en otros sitios, "se han hallado calzadas lateralmente con piedras, y colocadas verticalmente a cerca de 1 metro debajo del nivel del suelo" (Liberani \& Hernández 1951: 115).

Cupo a Florentino Ameghino publicar por primera vez la imagen de la urna exhumada por Liberani (Ameghino 1881: Lám. xI): la pieza ${ }^{\circ} 371$ de nuestro 


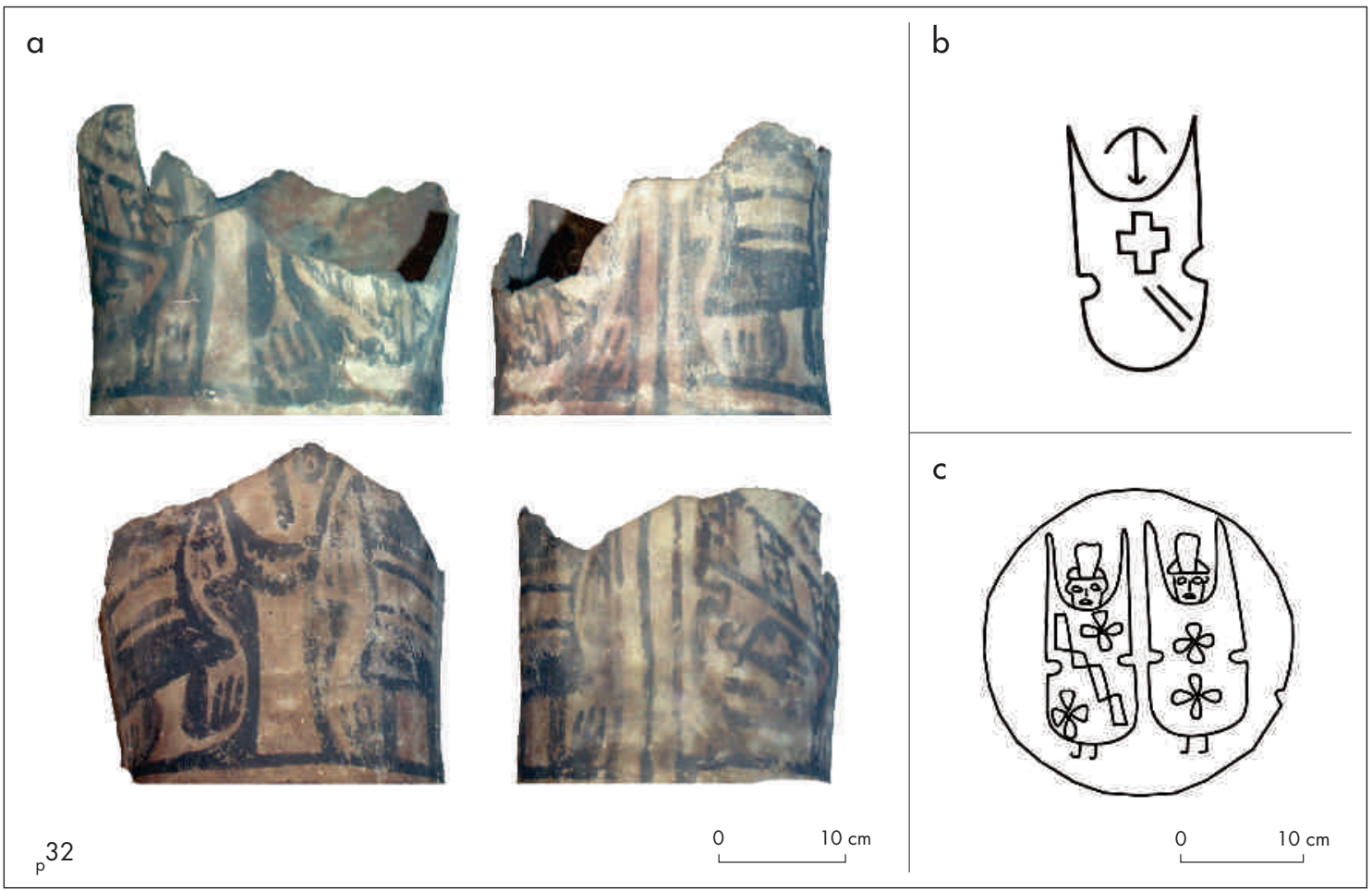

Figura 4: a) iconografía del cuello de 32 , correspondiente a la colección Quiroga del Museo Etnográfico de la UBA; b) figura escutiforme grabada en el sitio Piedra Pintada del Portezuelo, en Andalhuala, provincia de Catamarca (Quiroga 1901:190, 1992: 263); c) disco de bronce de la Colección Zavaleta procedente de Cachi, tomado de Quiroga (1901: 190). Figure 4: a) iconography on the neck of 32 , from the Quiroga Collection of the Museo Etnográfico de la UBA; $\boldsymbol{b}$ ) escutiforme figure engraved at the Piedra Pintada site at Portezuelo, in Andalhuala, Catamarca Province (Quiroga 1901: 190, 1992: 263); c) bronce disc from the Zavaleta Collection, from Cachi, taken by Quiroga (1901: 190).

registro (de aquí en más 371 , fig. 3a) ${ }^{1}$. El autodidacta mercedino no hizo referencia alguna a los personajes. Por su parte, Ambrosetti, en una de sus Notas de arqueología calchaquí, dio a conocer un ejemplar con dos personajes con escudos similares a los de la urna de Loma Rica, sin realizar comentario sobre los mismos (Ambrosetti 1899: 181), concentrándose en cambio en las figuras zoomorfas del cuerpo de la vasija (fig. 4a). Esta última urna sí fue localizada en el acervo del Museo Etnográfico de la Universidad de Buenos Aires, pudiéndose determinar que en el reverso ostenta representaciones humanas portando idéntico tipo de escudos, aunque con variaciones en los diseños de las guardas diagonales que se disponen sobre los mismos.

Ambrosetti también ilustró en sus Notas (1898: 56) la imagen aislada de una representación humana de cuerpo completo correspondiente a una urna funeraria de la colección de Max Schmidt (fig. 3b), en la cual se observa una larga túnica ceñida a la cintura -esto es, en forma de clepsidra o reloj de arena - decorada a todo lo largo en su porción central con dos motivos de aves y en sus cuatro esquinas (hombros y falda) por círculos con un punto interior. Para Ambrosetti, los dos triángulos negros sobre la cabeza corresponderían a un tocado

Adán Quiroga, por su parte, incluyó varias imágenes de urnas con representaciones de humanos de cuerpo entero en sus obras Folklore calchaquí (1992 [1897]) y La cruz en América (1901). Son de destacar algunos detalles de la representación del personaje de la derecha de 1471 (fig. 3c): el mismo ostenta dos cabezas de color negro. Una parece ser la cabeza del propio individuo, mientras que la de la derecha aparenta corresponder a un cráneo trofeo dispuesto sobre el hombro del personaje. Finalmente, entre los pies de éste cabe reconocer una tercera cabeza triangular, con una de las formas habituales de representación de las cabezas de serpientes. El personaje de la izquierda, por su parte, exhibe un escudo decorado con una serpiente; 
el rostro negro; y un posible tocado sobre la cabeza de una longitud aproximadamente similar a la de todo el cuerpo de la figura humana que lo porta.

Atendiendo ahora a la cuestión de las combinaciones en una misma pieza, vemos que en 369 (fig. 3d) coexiste un personaje con atuendo en forma de clepsidra con otro, en la mejilla derecha, portando un escudo que oculta su cuerpo. En cambio, 32 presenta la diferencia de atuendos entre caras: de un lado ambos personajes presentan cuerpo en forma de clepsidra; del otro, los dos portan escudos (fig. 4a).

A propósito de la imagen humana del reverso de 1461 (fig. 3e), Quiroga insistió con su tesis acerca de que lo que se representaba por encima de la cabeza del personaje es el algarrobo en torno al cual se celebraba la fiesta del Chiqui (Quiroga 1992 [1897]: 329). Las dos imágenes del anverso, idénticas entre sí, apoyan en cambio la idea de que se trata en todos los casos de ornamentos confeccionados de plumas u otros materiales. Y refuerza nuestra opinión el siguiente caso que presenta Quiroga para demostrar su hipótesis acerca de que se trata de la representación del Chiqui: las figuras humanas con escudos del cuello de 52 (fig. 3f).

Quiroga fue también pionero en advertir la intertextualidad del motivo del personaje humano con escudo al reconocerlo sobre distintos soportes (Quiroga 1901:189-191). Lo identificó tanto en el arte rupestre de Andalhuala (fig. 4b) como en un disco metálico procedente de Cachi (fig. 4c).

\section{Caracterización de los motivos como "guerreros"}

Algunos años después de la muerte de Quiroga, Outes efectuaría una primera compilación de la cerámica reunida por el Museo de La Plata durante la primera época de la arqueología calchaquí (Outes 1907). Una pieza de esas primeras colecciones resulta muy relevante para el tema de este trabajo. Se trata de un aríbalo con personajes pintados en su cuello que guardan algunas similitudes con los anteriormente descriptos: principalmente la cabeza, el tocado y los pies; y, en segundo lugar, la disposición de los brazos hacia arriba, que asemeja a la terminación en punta de las corazas (fig. 5a).

En el caso de los tres personajes del cuello del aríbalo ( 1454 ) no podemos determinar si portan o no escudos. De no ser el caso, sus cuerpos circulares aparecen en extremo voluminosos. Sus cabezas triangulares no se diferencian en nada de muchas de las vistas hasta aquí, al igual que la representación de ojos, narices, bocas y lo que parecen ser penachos de plumas sobre las cabezas. Lo mismo cabe decir de la representación de los pies y de los brazos alzados (Velandia 2005: 178, Marchegiani et al. 2009: 76, Nastri 2014: 95). ¿Cuál es el valor de estas similitudes? El de sugerir una conexión cronológica: las piezas inca provinciales incorporaban motivos, técnicas, materias primas y/o tradiciones tecnológicas propias de las poblaciones conquistadas (Williams 2004: 228). Es entonces significativo que todos los motivos pintados en el aríbalo (ave, serpiente, reticulados) sean parte del repertorio iconográfico santamariano, con la salvedad de las particularidades que exhiben las representaciones humanas del gollete (Nastri 1999: 388-396). Cabe pensar entonces en la contemporaneidad de las urnas santamarianas fase IV con la invasión incaica, tal como propusieran Perrotta y Podestá (1978: 537). Como alternativas, cabe contemplar la posibilidad de que los artesanos productores de los aríbalos recuperaran un significante del pasado reciente calchaquí, tal como se deriva de la postulación de Weber de la fase IV como pre-inca (Weber 1978: 82); o bien que las piezas con antropomorfos fueran post incaicas, siendo entonces el caso el de la expresión de un motivo introducido por las huestes cuzqueñas, tal como sugiriera Weber para el caso de los motivos de serpiente y aves del aríbalo de Lafone presentes en las urnas fase $\mathrm{v}$, atendiendo a situaciones comparables observadas en Perú en relación con la morfología de las piezas locales imitaciones de las cuzqueñas (Weber 1978: 82). Esto último sería, no obstante, contradictorio con el fechado obtenido por Cigliano en Ampajango (Weber 1978: 81, 83). Volveremos sobre esta cuestión más adelante.

Fue aparentemente el mismo Lafone Quevedo el primero en referirse a las figuras humanas de las urnas santamarianas (fig. 3f) como "guerreros" (Lafone Quevedo 1908: 346). Para la misma época Bruch registraba otro caso de escutiforme grabado en una roca sobre el camino entre Loma Rica y Andalhuala (Bruch 1911: 119). En la imagen de la figura 5.b se reconocen: la escotadura a la altura de la cintura y el penacho en forma de ancla invertida por sobre la porción superior del escudo, el cual tiene terminaciones laterales alargadas hacia arriba. El soporte rocoso habría impuesto ciertas restricciones para la representación de detalles, que en cambio son objeto de atención en la pintura sobre cerámica. Así puede verse cómo en los antropomorfos de una misma cara de ${ }_{\mathrm{p}} 22$ se 


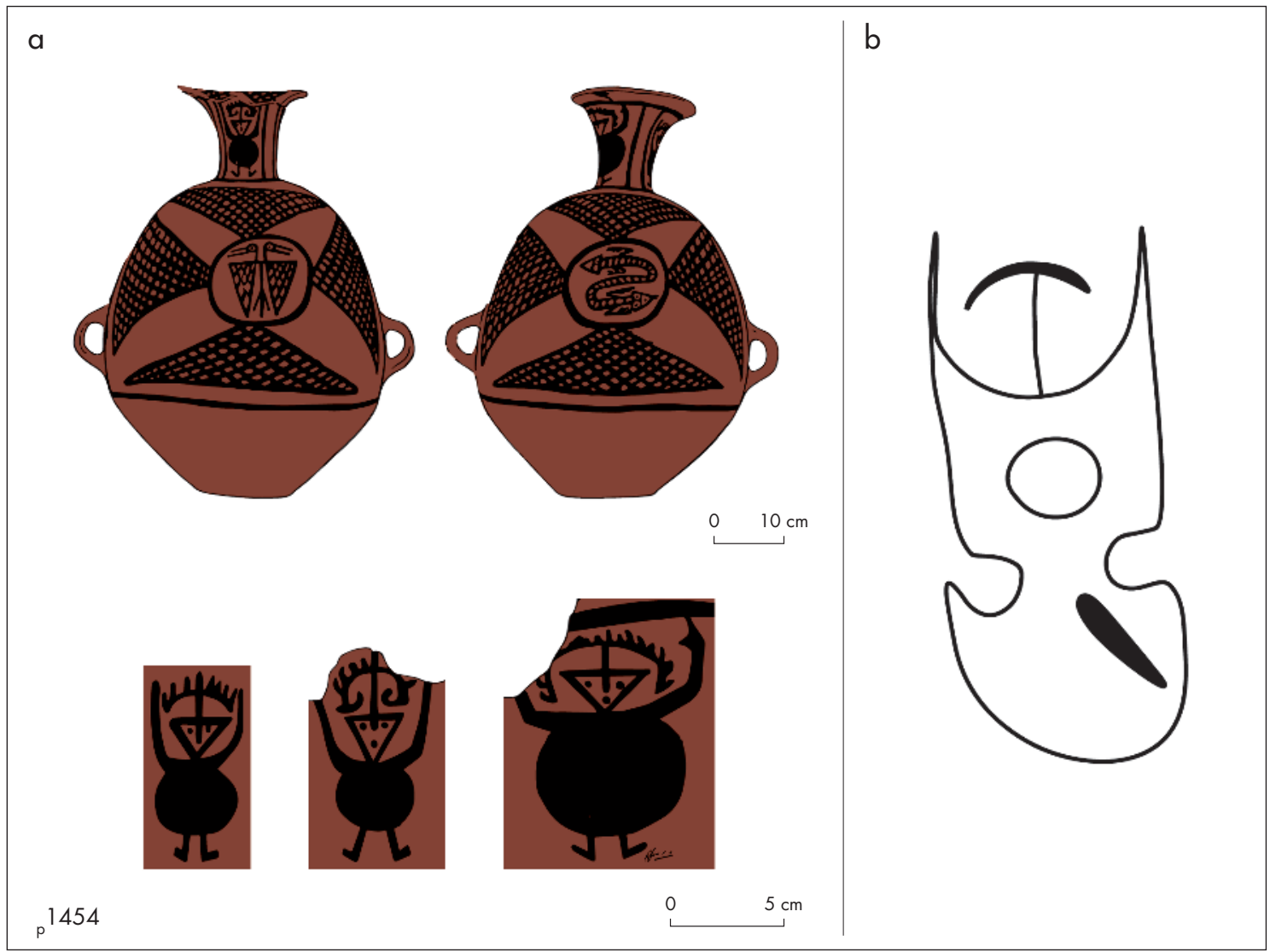

Figura 5: a) anverso y reverso de 1454 y detalle de las representaciones de personajes humanos del gollete según Lafone Quevedo (1908: 392-394); b) escutiforme grabado en una roca inmueble en las inmediaciones de Loma Rica de Shiquimil, pcia. de Catamarca (Bruch 1911: 119). Sin escala. Figure 5: a) front and back sides of 1454 and detail of representations of human figures on the neck, as per Lafone Quevedo (1908: 392-394); b) escutiforme engraved on a rock wall near Loma Rica de Shiquimil, Catamarca Province (Bruch 1911: 119). No scale.

apela a motivos diminutos para establecer "diferencias sutiles" (Nastri 2005-2006: 256, 2009: 102) entre uno y otro personaje (fig. 6a): puede observarse el contraste tanto en la forma de los penachos como en la presencia diferencial de pendientes en las orejas (o también podría tratarse de trenzas de los tocados). ${ }^{2}$ De esta manera se expresaba en el arte santamariano la noción de desequilibrio al interior de la gemelidad, tan difundida en el arte de la América indígena (Levi Strauss 1992: 292). ${ }^{3}$

Márquez Miranda incluyó en sus trabajos varios ejemplos de urnas con representaciones humanas en sus mejillas, también sin emitir opinión acerca de las mismas. En la primera de ellas - $_{\mathrm{p}} 292$ - resulta notorio el contraste entre los personajes de cada una de las mejillas del reverso (fig. 6b). El de la izquierda presenta su cabeza de forma redondeada, con un tocado bajo, a la altura de las orejas; el de la derecha tiene por el contrario una suerte de penacho, encima de la bóveda, la cual tiene forma aproximadamente trapezoidal. A este último le falta indicación de pies por debajo de su coraza, a diferencia del personaje de la izquierda, que los tiene claramente representados. Las decoraciones de las corazas son también totalmente diferentes. La del personaje de la izquierda consiste de dos bandas cruzadas con motivos escalonados-espiralados en una y simplemente espiralados en la otra; la del personaje de la derecha consiste en dos serpientes rectilíneas dispuestas con sus cabezas orientadas en direcciones opuestas (una hacia arriba y otra hacia abajo). En el anverso la decoración de la coraza del personaje de la izquierda es muy similar a la de su homólogo del reverso; la del personaje de la derecha en cambio, no se parece a ninguna otra: consiste en una banda central vertical y dos motivos curvos a cada lado. 


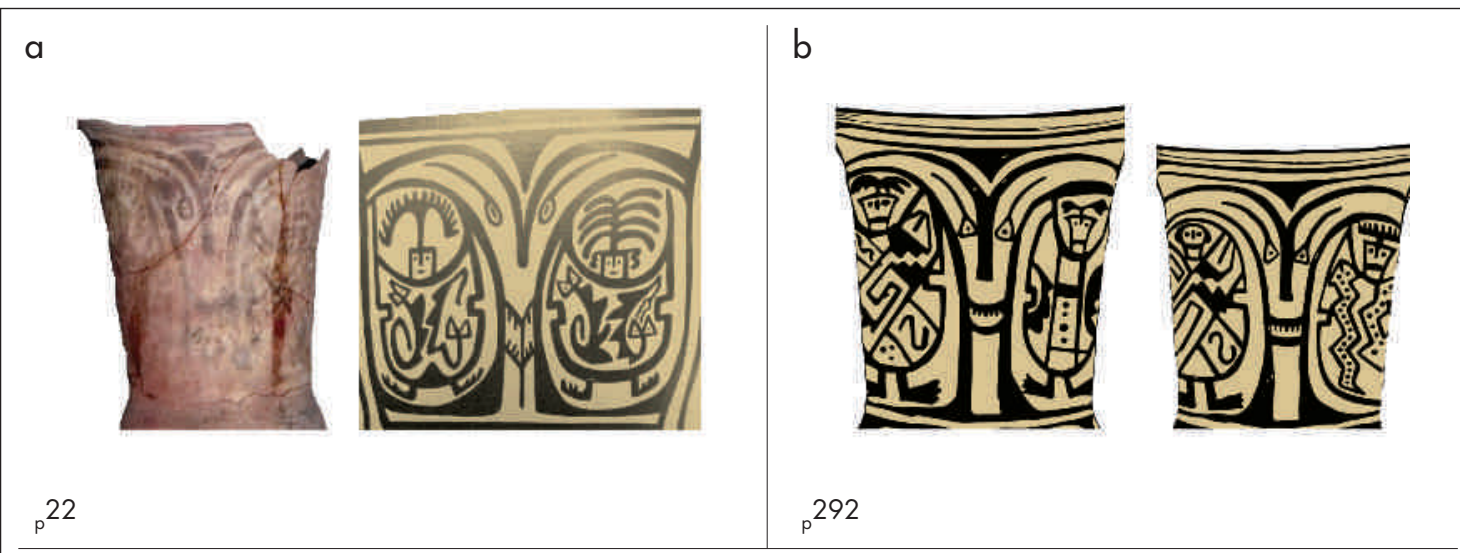

C
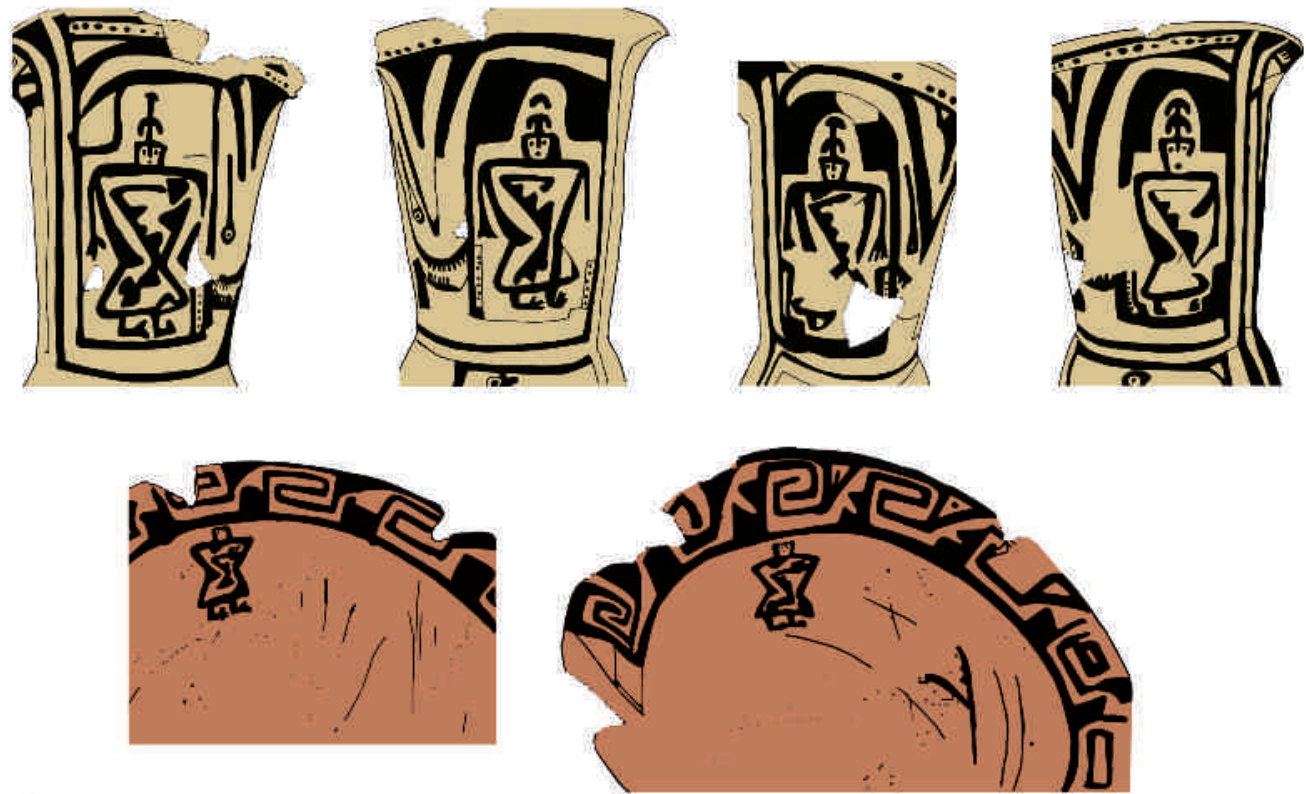

$p^{467}$

Figura 6: a) iconografía del cuello de 22 (reverso según Wagner \& Wagner 1934: 110); b) iconografía del cuello de 292 según Márquez Miranda (1939: 308, 321, Velandia 2005: 183); c) detalles de las representaciones en el cuello de 467. Figure 6: a) iconography on the neck of 22 (back side, as per Wagner \& Wagner 1934: 110); b) iconography on the neck of 292 as per Márquez Miranda (1939: 308, 321, Velandia 2005: 183); c) detaails of representations on the neck of 467.

La siguiente urna ilustrada por Márquez Miranda - 467- también procede de la misma localidad de Punta de Balasto, pero a diferencia de la anterior, presenta todos sus personajes vestidos con atuendos en forma de clepsidra (fig. 6c). Los cuatro tienen idéntico tocado arriba de la bóveda craneal, compuesto de dos elementos al modo de dos tumis superpuestos. En el anverso las cabezas de ambos personajes son similares: la del de la izquierda algo más rectangular que trapezoidal y la del de la derecha, trapezoidal. Esta última tiene en su costado izquierdo una probable indicación de pelo. Las decoraciones de ambas túnicas difieren y mientras que el personaje de la izquierda presenta sus pies en posición de simetría refleja uno con otro, el de la izquierda los dispone en forma de traslación: ambos orientados hacia la derecha. En el reverso de la misma pieza, la erosión 


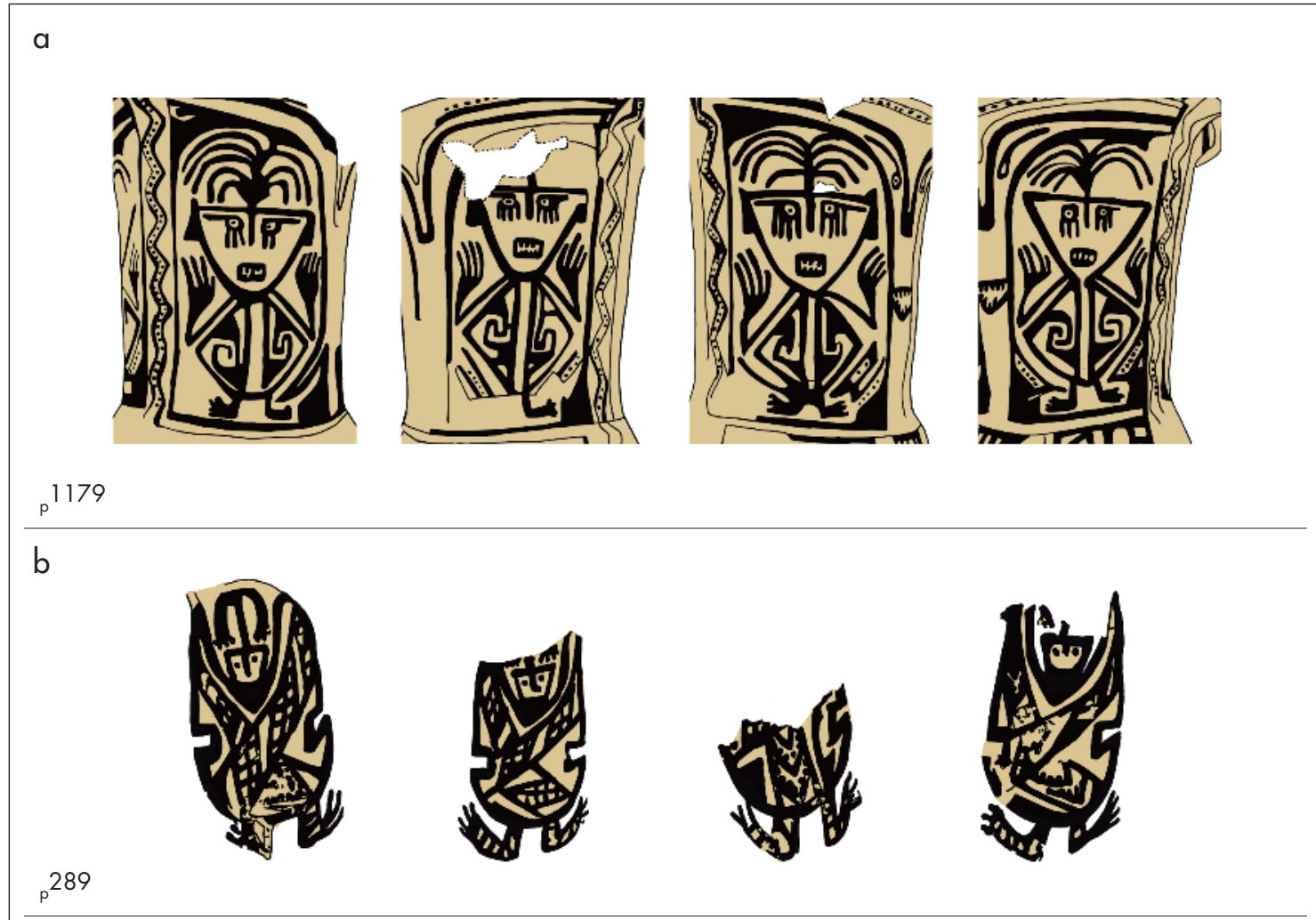

C
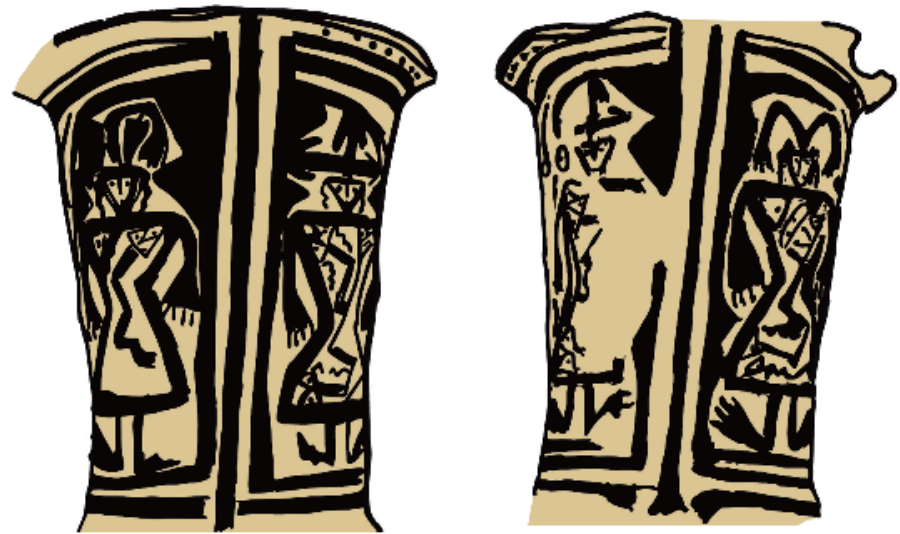

286

0

$10 \mathrm{~cm}$

Figura 7: a) detalles de las representaciones en el cuello de 1179; b) detalles de las representaciones en el cuello de 289; c) detalles de las representaciones en el cuello de ${ }_{\mathrm{p}}^{286}$. Figure 7: $\boldsymbol{a}$ ) details of representations on the neck of $1179 ; \boldsymbol{b}$ ) details of representations on the neck of $289 ; c$ ) details of representations on the neck of 286.

no permite apreciar las figuras completas, pero hasta donde puede observarse no se advierten diferencias con el anverso. En el lado interno de la vasija existen otras dos representaciones humanas similares a las anteriores, de aproximadamente un tercio del tamaño de las de la superficie externa. A diferencia de éstas, carecen de tocado, pero igualmente que las primeras, presentan los pies en traslación y ostentan serpientes en zig zag como decoraciones de la vestimenta. Llama la atención la ausencia de brazos. En lo que respecta a los 
tocados cefálicos la ausencia podría deberse al hecho de que queda poco espacio entre la porción superior de la cabeza del personaje y la banda perimetral que adorna el borde interior de la pieza. Podría ser el caso de que el personaje se hubiera pintado con posterioridad al motivo de la banda perimetral interna compuesta de diseños geométricos. Más allá de esto, cabe destacar la similitud en el vestido y el diseño contenido en este, entre los antropomorfos del interior de la pieza y los de las cuatro mejillas.

En su voluminosa obra Los diaguitas, Márquez Miranda dio a conocer una gran cantidad de información inédita de la colección Muniz Barreto, entre la cual se incluyen tres urnas con representaciones humanas en el cuello (Márquez Miranda 1946). La urna 1179 (fig. 7a), procedente de Shiquimil, es quizá la más excepcional de toda la muestra, pues es la única cuyos personajes de las mejillas no visten túnicas ni portan escudos. Presentan un cuerpo de forma romboidal similar al de los batracios que se pintaban en el cuerpo de las vasijas (cfr. fig. 3f). La cabeza y las extremidades inferiores son en cambio del tipo corriente, salvo por el hecho del tamaño desproporcionadamente grande de la cabeza. Finalmente cabe destacar la presencia de lágrimas, hecho posibilitado por el mayor tamaño aludido, que permite la exhibición de detalles menores en los rostros.

La segunda vasija de interés incluida en Los diaguitas es 289 , la cual presenta cuatro personajes ataviados con las ya clásicas corazas con escotadura y penachos por sobre la cabeza (fig. 7b). Lo novedoso de esta pieza reside en el hecho de la existencia de dos representaciones antropomorfas adicionales en los laterales de la vasija: se trata de sendas cabezas humanas invertidas, de cuyos cuellos se desprenden grecas cubriendo todo el campo de las bandas laterales hasta el borde superior de la pieza (Velandia 2005: 179, Nastri 2008: 21).

\section{El valor cronológico de los motivos antropomorfos de las mejillas}

En su siguiente obra "Ensayo de clasificación tipológicacronológica de la cerámica santamariana” (Márquez Miranda \& Cigliano 1957-1959), Márquez Miranda abordó finalmente el tema de las características de la decoración de las urnas santamarianas. Los autores discriminaron allí dos "facies" cronológicas en el estilo: la primera caracterizada por el uso de tres colores en la decoración; la segunda, por la reducción de la cantidad de colores a dos: negro y blanco. Ejemplifican esta última con un dibujo de ${ }_{\mathrm{p}} 286$, procedente de Las Mojarras, Catamarca (fig. 7c), la cual constituye otro caso de forma clásica de representación de personajes con atuendos en forma de clepsidra (Márquez Miranda \& Cigliano 1957-1959: 15, Velandia 2005: 181, Nastri \& Coll Moritan 2009: 733). La pieza exhibe una poco frecuente uniformidad en los vestidos y la decoración de los mismos. Esta última consiste en los cuatro casos de ofidios bicéfalos. Las variaciones se dan en los tocados: las figuras del anverso en lugar de penachos ostentan un adminículo en forma de cruz, con terminaciones en forma de "punta de flecha" en sus extremos superior y laterales. No se puede dejar de advertir la similitud de estos ornamentos con objetos metálicos como los hallados por Ambrosetti en tumbas de La Paya (Ambrosetti 1902: 121), en el Valle Calchaquí.

Los autores destacaron las "figuras antropomorfas" como "los caracteres más importantes" de la facie bicolor, al tiempo que señalaron el hecho de la representación ocasional de cráneos trofeo (Márquez Miranda \& Cigliano 1957-1959: 14-15). Ilustraron el tema con el caso de 285 (fig. 8a), en la cual se puede identificar que la cabeza cercenada es portada por un personaje sin tocado en la cabeza y vestido con atuendo en forma de clepsidra con decoración de serpiente rectilínea.

Márquez Miranda y Cigliano consideraron que el carácter "neto" de las diferencias entre las variedades tricolor y bicolor de urnas santamarianas permitirían sostener "que pertenecen a dos períodos distintos" (Márquez Miranda \& Cigliano 1957-1959: 16). Al considerar las asociaciones contextuales de las urnas en los yacimientos excavados por las misiones Muniz Barreto en el Valle de Santa María, los autores encontraron que los lugares de entierro que contienen uno y otro tipo o facie cerámica estaban espacialmente segregados (tabla 1).

Casi contemporáneamente con su trabajo sobre las variedades del santamariano, Márquez Miranda y Cigliano dieron a conocer los resultados de sus trabajos en Rincón Chico (Márquez Miranda \& Cigliano 1961), donde recuperaron una urna con representaciones antropomorfas (fig. 8b) en una cámara sepulcral ubicada en el bajo, en las proximidades del río Santa María. Se trata de una vasija - 1481- que los autores incluyeron en su tipo santamariano bicolor y que más recientemente fue incluida por Marchegiani et al. (2009: 77) en el tipo "urnas negro sobre rojo". El tamaño y la ubicación de las figuras; la forma de las cabezas y de los penachos; 


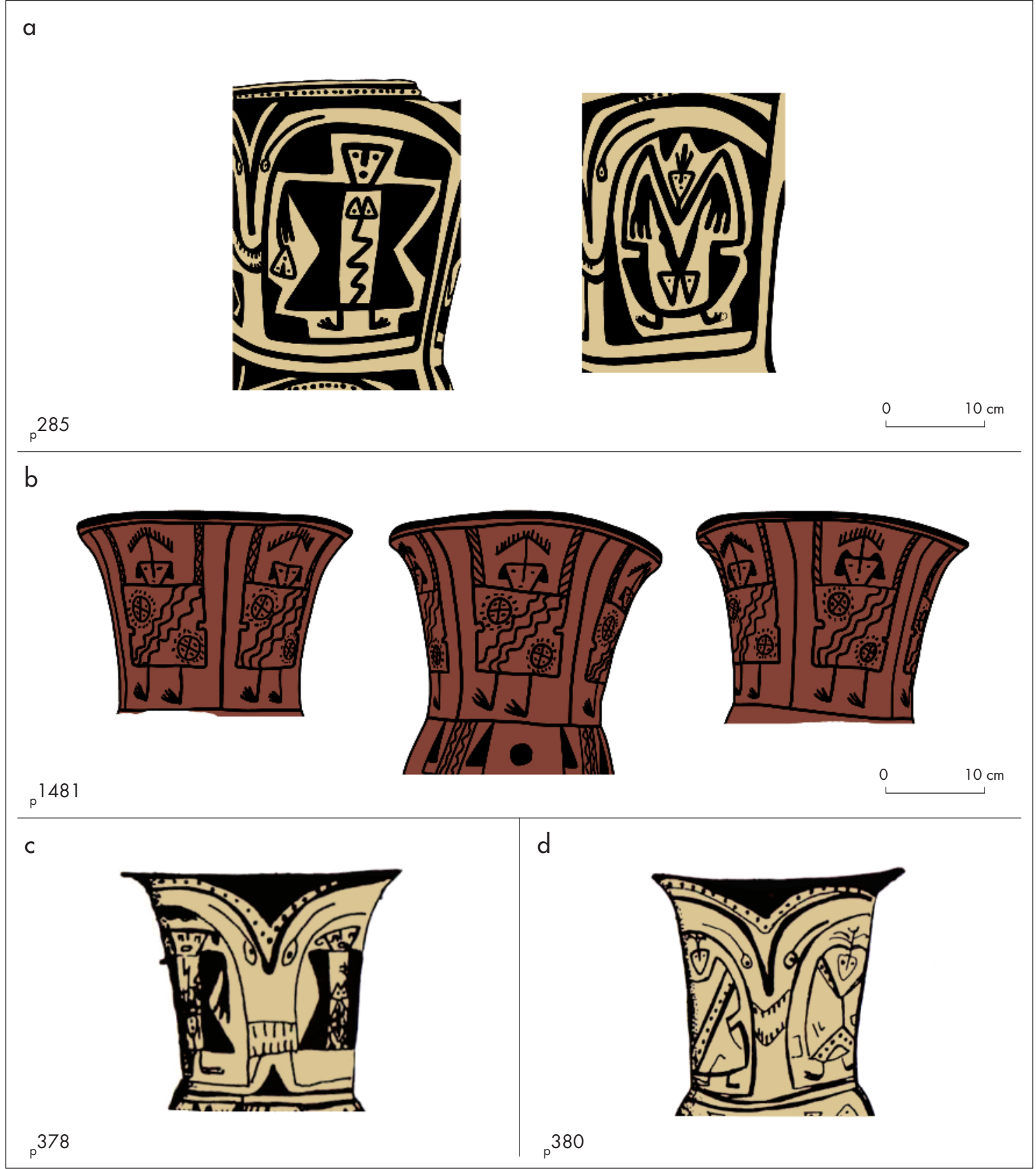

Figura 8: a) detalles de las representaciones en el cuello de 285 ; b) iconografía del cuello de 1481 ; c) iconografía del cuello de 378 (tomado de Weber 1978: 86); d) iconografía del cuello de 380 (tomado de Weber 1978: 86). Figure 8: a) details of representations on the neck of $285 ; \boldsymbol{b}$ ) iconography on the neck of $1481 ; c$ ) iconography on the neck of 378 (taken from Weber 1978: 86); d) iconography on the neck of 380 (taken from Weber 1978: 86).

el hecho de que se puede reconocer que los personajes portan escudos o visten corazas; son todos elementos que permiten asociar estas figuras a aquellas que venimos describiendo. Las prolongaciones hacia arriba de las protecciones corporales de los personajes, a los costados de sus cabezas, son otros rasgos que pueden advertirse en algunas de las piezas de la serie. Solo en el aríbalo de Lafone (fig. 5a) queda claro que lo que ocupa 
Tabla 1. Separación contextual de las facies santamarianas en los cementerios del Valle de Santa María excavados por las misiones Muniz Barreto (Basado en Márquez Miranda \& Cigliano 1957-1959). Table 1. Contextual separation of Santa María facies in Santa María Valley cemeteries excavated by the Muniz Barreto missions (Based on Márquez Miranda \& Cigliano 1957-1959).

\begin{tabular}{c|c|l|l|l}
\hline LOCALIDAD & SITIO & $\begin{array}{l}\text { DESCRIPCIÓN DE } \\
\text { LA SEPULTURA }\end{array}$ & $\begin{array}{l}\text { VARIEDAD } \\
\text { DE URNAS } \\
\text { IDENTIFICADA }\end{array}$ & $\begin{array}{l}\text { OTROS TIPOS } \\
\text { CERÁMICOS } \\
\text { PRESENTES }\end{array}$ \\
\hline Famabalasto & Cistas & $\begin{array}{l}\text { Santa María } \\
\text { Tricolor }\end{array}$ & \\
\hline Famabalasto & Tumbas múltiples & $\begin{array}{l}\text { Santa María } \\
\text { Bicolor }\end{array}$ & $\begin{array}{l}\text { Famabalasto } \\
\text { y Belén }\end{array}$ \\
\hline Chiquimil & Cementerio II & Cistas & $\begin{array}{l}\text { Santa María } \\
\text { Bicolor }\end{array}$ & \\
\hline Chiquimil & Cementerio III & & San José & \\
\hline
\end{tabular}

el mismo lugar son los brazos extendidos hacia arriba del personaje. Estas protuberancias verticales presentan en 1481 un "relleno" pintado algo diferente al del escudo o coraza. Éste a su vez presenta la escotadura en la cintura habitual en las imágenes antropomorfas de ese tipo, pero la forma cuadrada del adminículo protector es absolutamente original. La banda diagonal que cruza el escudo o coraza es una forma de decoración frecuente en las urnas fase IV, pero nunca en la forma de líneas onduladas. Más adelante expondremos algunas ideas acerca de las implicancias de la presencia de este motivo. Por el momento nos limitaremos a señalar que en el escudo o coraza portada por cada personaje los motivos en cuestión se disponen a cada lado de una línea ondulada oblicua central; uno ubicado en la porción superior, y el opuesto en la inferior del adminículo defensivo. Por otra parte, el diseño de los pies de los personajes también sale de lo corriente, al tiempo que el peinado que exhiben es distinto a cualquier otro visto en antropomorfo con escudo, según lo que se conoce hasta el momento.

Es de destacar el hecho de la presencia de cuentas de vidrio en la cámara sepulcral en la que se encontrara p 1481, constituyendo hasta la fecha la única pieza con antropomorfos en el cuello a la cual puede asignársele una antigüedad determinada (hispano indígena) a partir de elementos contextuales (Márquez Miranda \& Cigliano 1961: 191).

Recién en la década siguiente, con el estudio de Ronald Weber de la colección Zavaleta del Museo de Chicago el tema de la cronología adquiriría nuevos bríos, siempre en relación con piezas procedentes del Valle de Santa María. Weber dio a conocer 37 ejemplares de urnas santamarianas de la colección Zavaleta que fueran adquiridas por el Museo Field de Historia Natural de Chicago (Weber 1978). Lamentablemente solo proporcionó ilustraciones de 26 casos de la muestra, entre los cuales se cuentan dos piezas con representaciones humanas de cuerpo completo en las mejillas. Weber consideró otros 62 casos de urnas publicadas para armar su seriación del estilo (Weber 1978, 1981; Nastri 2009). En ésta, de las 12 piezas que presentan el motivo objeto del presente trabajo, 9 fueron clasificadas como correspondientes a la fase IV y las restantes 3 a la fase v (Weber 1981: 15-16). ${ }^{4}$ De ambas urnas del Museo de Chicago, Weber solo ilustra el anverso (Weber 1978: 86), siendo las representaciones antropomorfas de las mejillas del tipo de las ya conocidas: con atuendo en forma de clepsidra las de 378 (fig. 8c); con escudo las de 380 (fig. 8d). Llama la atención la ausencia de escotadura en el escudo del antropomorfo de la mejilla derecha de la última pieza.

Podestá y Perrota aplicaron la seriación de Weber a la colección Muniz Barreto del Museo de La Plata, completando las características de cada fase y agregando una más, al principio de la serie (Nastri 2009). Las piezas de nuestro interés fueron ubicadas en la fase IV, respecto de la cual señalaban que: “...es común el diseño de guerreros como en ciertos aríbalos incaicos [...] Característica es la representación de cabezas trofeo" (Podestá \& Perrotta 1973: 12). González también des- 

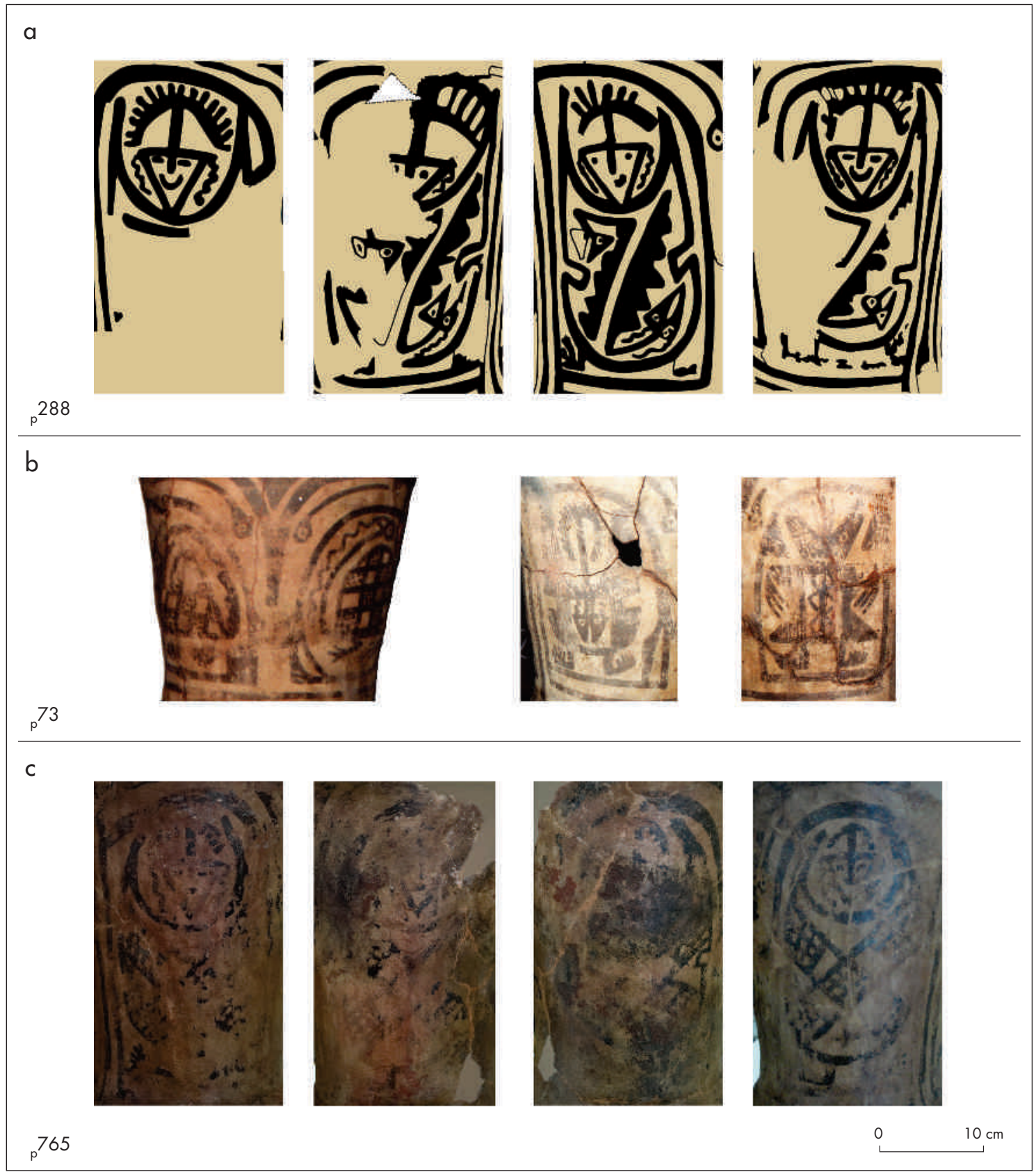

Figura 9: a) detalles de las representaciones en el cuello de 288; b) detalles de las representaciones en el cuello de 73 ; c) detalles de las representaciones en el cuello de ${ }_{p} 765$. Figure 9: $a$ ) details of representations on the neck of $288 ; \boldsymbol{b}$ ) details of representations on the neck of $73 ; c)$ details of representations on the neck of 765 .

tacó el hecho de la similitud de los escutiformes de las urnas fase iv (fig. 9a) con los de ciertos aríbalos incaicos (González 1977: 330), pero, otra vez, sin mencionar ejemplos específicos de piezas cuzqueñas.
Calderari y Williams dieron a conocer a comienzos de los años '90 un segundo caso de urna roja con antropomorfos en las mejillas (Calderari \& Williams 1991: lám. I). Al igual que en el caso de la urna de Rincón Chico (fig. 8b), uno de los personajes presenta ambos 

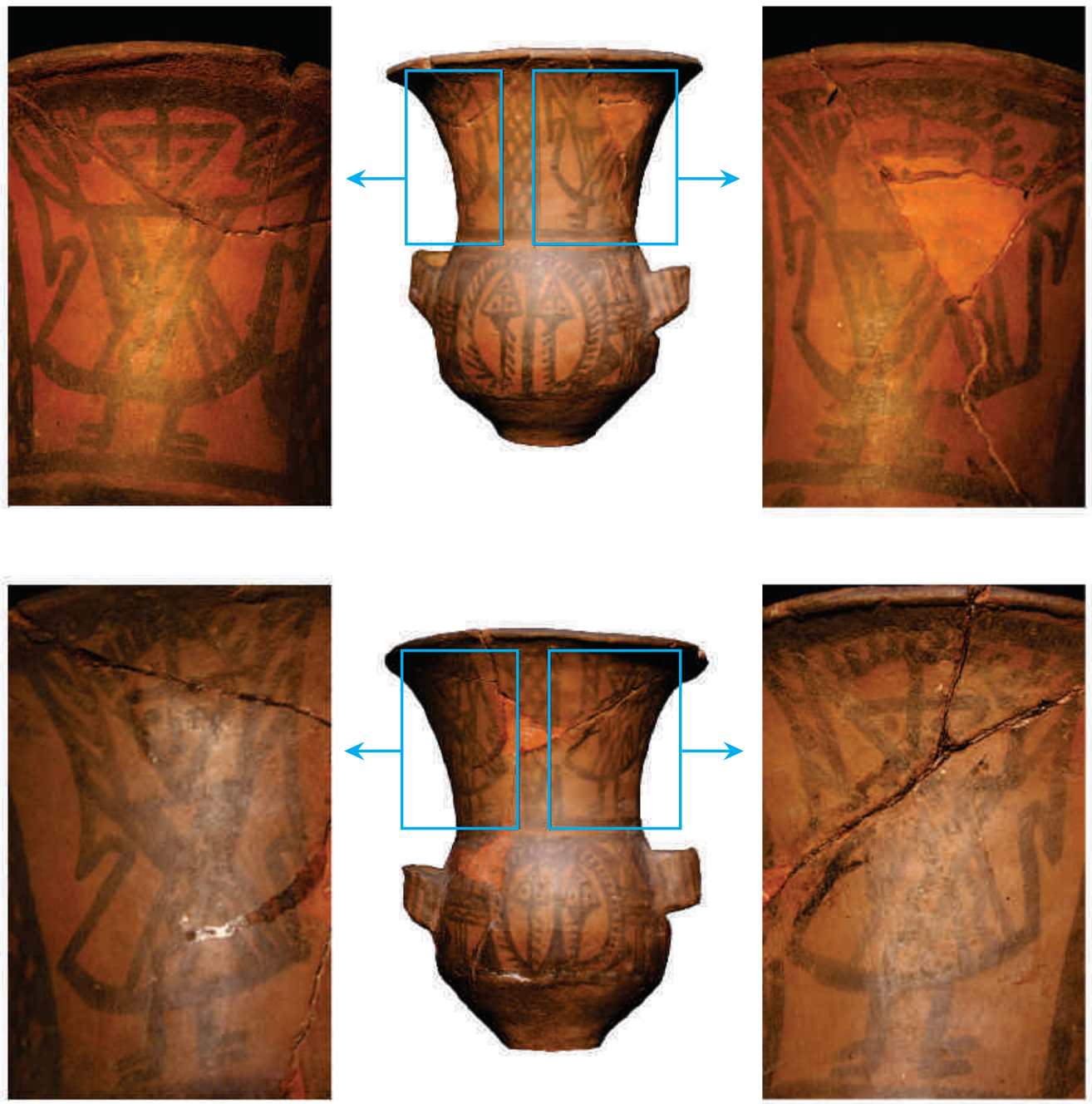

p 974

0

$10 \mathrm{~cm}$

Figura 10. Anverso y reverso de 974 , con detalles de las representaciones humanas de las mejillas. Figure 10. Front and back views of ${ }_{p} 974$, showing details of the human representations on the cheeks.

apéndices laterales superiores del escudo o coraza, relleno de líneas, en contraste con el resto del adminículo (fig. 10). Pero a diferencia de la pieza de Rincón Chico, en ésta la forma de los escudos no es rectangular, sino que tiene una forma similar a los modos en que se los representa el arte rupestre: contornos curvos con ángulos exteriores agudos en las axilas y terminados en punta hacia los laterales de las cabezas de los personajes. Estas últimas, por su parte, con su forma triangular, son en todo similares a las de las urnas santamarianas. La decoración de los escudos, consistente en el de la mejilla izquierda del anverso en la habitual superposición de bandas en forma de "X", se alteran (sensu Nastri 2009) en el resto de las mejillas mediante el desplazamiento de la posición de los segmentos tras el punto de intersección entre una y otra banda. En un caso el desplazamiento es tal que la forma descripta ya no es una "X", y se asemeja en cambio a una "N" invertida. 


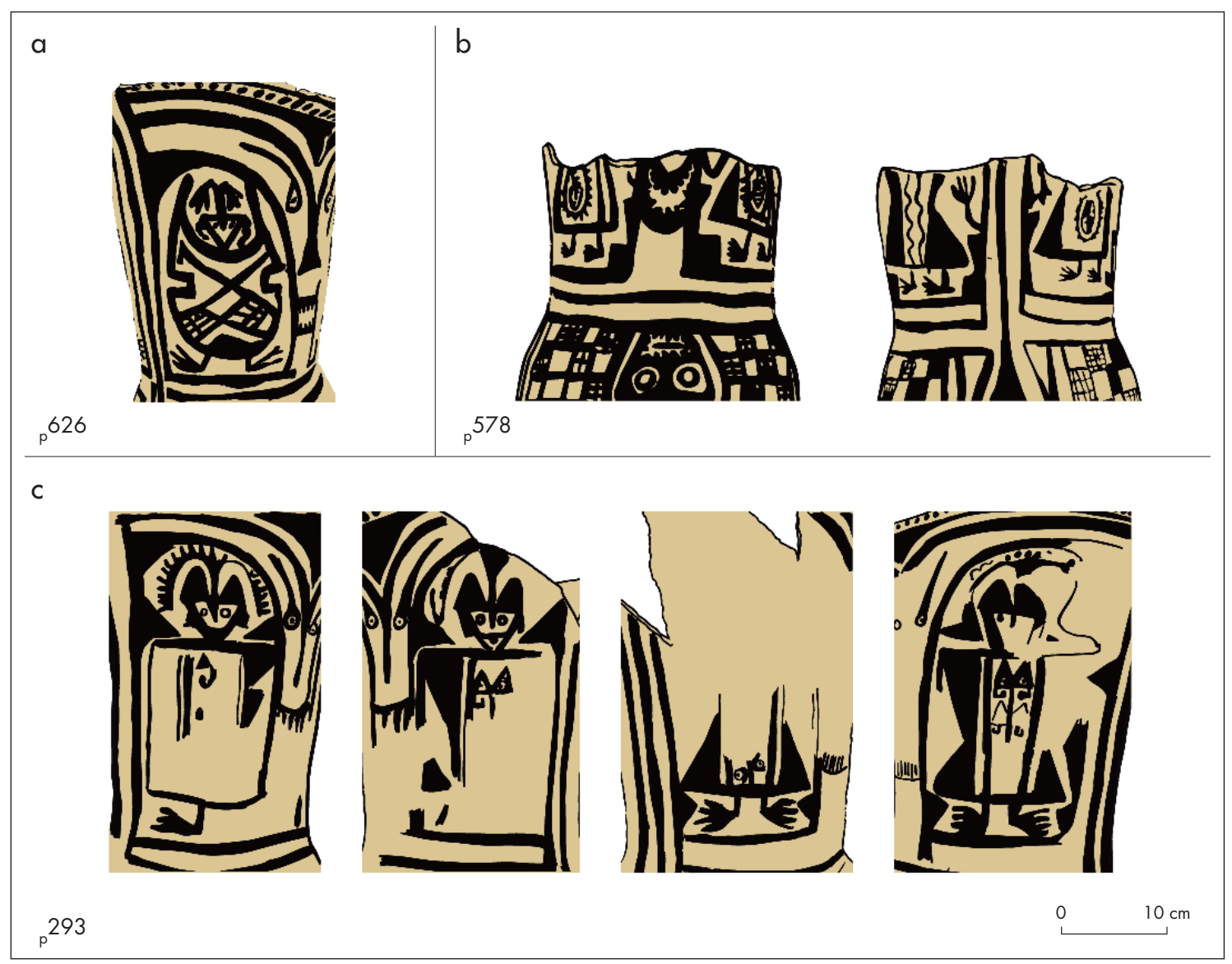

Figura 11: a) detalles de las representaciones humanas en la mejilla izquierda de 626; b) iconografía del cuello de 578, anverso y lateral; c) detalles de las representaciones en el cuello de 293. Figure 11: $a$ ) details of human representations on the left cheek of $626 ; \boldsymbol{b}$ ) iconography on the neck of 578 , front and side views; $c$ ) details of representations on the neck of ${ }_{p} 293$.

Hacia fines del siglo pasado uno de nosotros dio a conocer piezas relevantes de las colecciones de los museos Etnográfico de Buenos Aires (Tarragó et al. 1997: 229, Nastri 2005-2006: 260), Etnológico de Berlín (Nastri 1999: 387, 396, 2007: 461, 2008: 21, 28), de La Plata (Nastri 2008: 20, 21) y Arqueológico de Quilmes (Nastri 2007: 461). En el primero de los museos mencionados se documentó una interesante pieza en la cual coexisten en una misma cara un personaje con escudo y otro con atuendo en forma de clepsidra (fig. 9b). El primero -sobre la mejilla izquierda de ${ }_{\mathrm{p}} 73$ - presentaría la cabeza oculta tras escudo, sobresaliendo de la misma solo su penacho. Este caso podría constituir una pista respecto del uso de estos tocados: permitirían constatar la presencia del combatiente oculto tras el escudo. Tendría lógica entonces la ausencia de penachos en el caso de los personajes ataviados con túnicas. El personaje de la mejilla derecha, con vestimenta en forma de clepsidra, por su parte, pareciera portar una máscara, pues su rostro aparece negro, hundido en la parte superior frontal, con tres plumas colocadas en la frente.

Los personajes con corazas de la siguiente pieza, del Museo de Roma (Nastri \& Vietri 2004: 374), se ajustan en cambio al modo más convencional de representación del motivo (fig. 9c). Llama la atención la similitud de esta pieza con otras dos de la muestra $-_{\mathrm{p}} 87$ (fig. 1) y p 626 (fig. 11a)-: tanto las decoraciones de los escudos como la forma de los penachos es idéntica, lo cual es una rara coincidencia, considerando la gran variedad vista en ambos atributos de los antropomorfos de las mejillas. Retomaremos este dato más adelante, en relación con la interpretación de la iconografía de las urnas negro sobre rojo. 


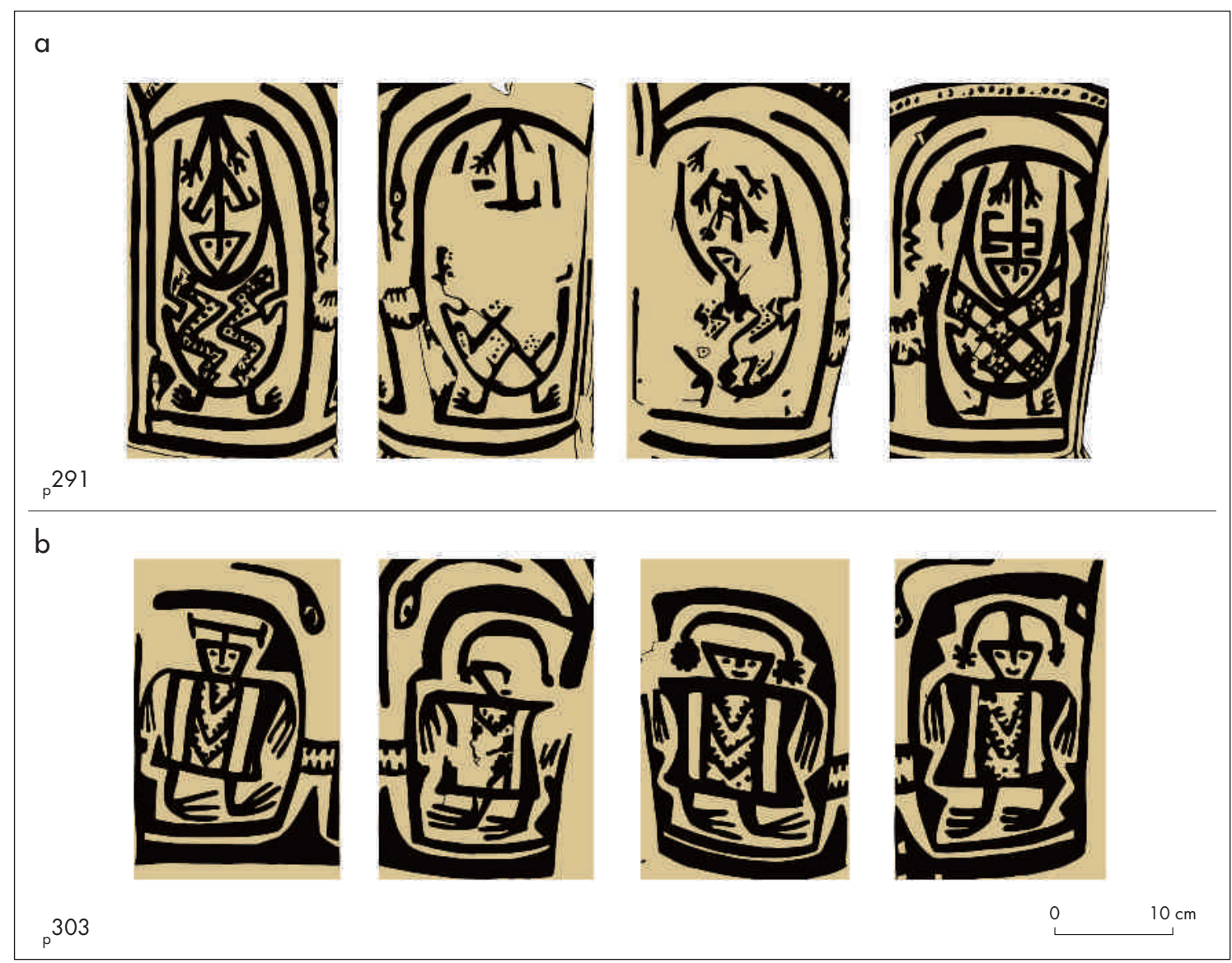

Figura 12: a) detalles de las representaciones humanas en el cuello de 291 ; b) detalles de las representaciones humanas en el cuello de 303. Figure 12: $a$ ) details of human representations on the neck of $291 ; \boldsymbol{b}$ ) details of human representations on the neck of 303.

\section{Cabezas cercenadas y relaciones con la figura de las largas cejas}

En una pieza del Museo de Berlín aparecen asociadas las figuras humanas de cuerpo completo de las mejillas con la temática del sacrificio de una manera diferente a las conocidas hasta el momento, según los antecedentes vistos de piezas presentadas por Quiroga (fig. 3c) y Márquez Miranda (fig. 8a). En la figura 11b puede apreciarse que es la "figura de las largas cejas" (Nastri 2008), o rostro antropomorfo central de la vasija, la entidad que porta en sus manos una indudable cabeza cercenada (en lugar del habitual puco), al tiempo que, a pesar de lo fragmentado del cuello se alcanzan a reconocer las partes inferiores de cuatro antropomorfos de cuerpo completo dispuestos, como es habitual, en las mejillas de la urna. Las características del motivo central aludido sirven como referencia para el reconocimiento del motivo en figuras de menor tamaño, como es el caso de los antropomorfos de las mejillas: 1) la cabeza cercenada que sostiene la figura de las largas cejas es de color negro; 2) está dispuesta al revés; 3) presenta las órbitas oculares como si estuvieran vacías; 4) presenta indicación de costura en la boca.

Esta pieza presenta así una pista clave para la comprensión general del fenómeno de las urnas santamarianas, pues permite inferir que, si el significado del referente de la figura de las largas cejas fue estable en la vida del género, el mismo no habría podido ser el infante contenido en la urna como víctima. La figura de las largas cejas tiene aquí atributos agresivos (Nastri 2008), propios de un sacrificador antes que de un sacrificado.

Velandia, quien volvió ya en el presente siglo sobre la colección Muniz Barreto del Museo de La Plata, 


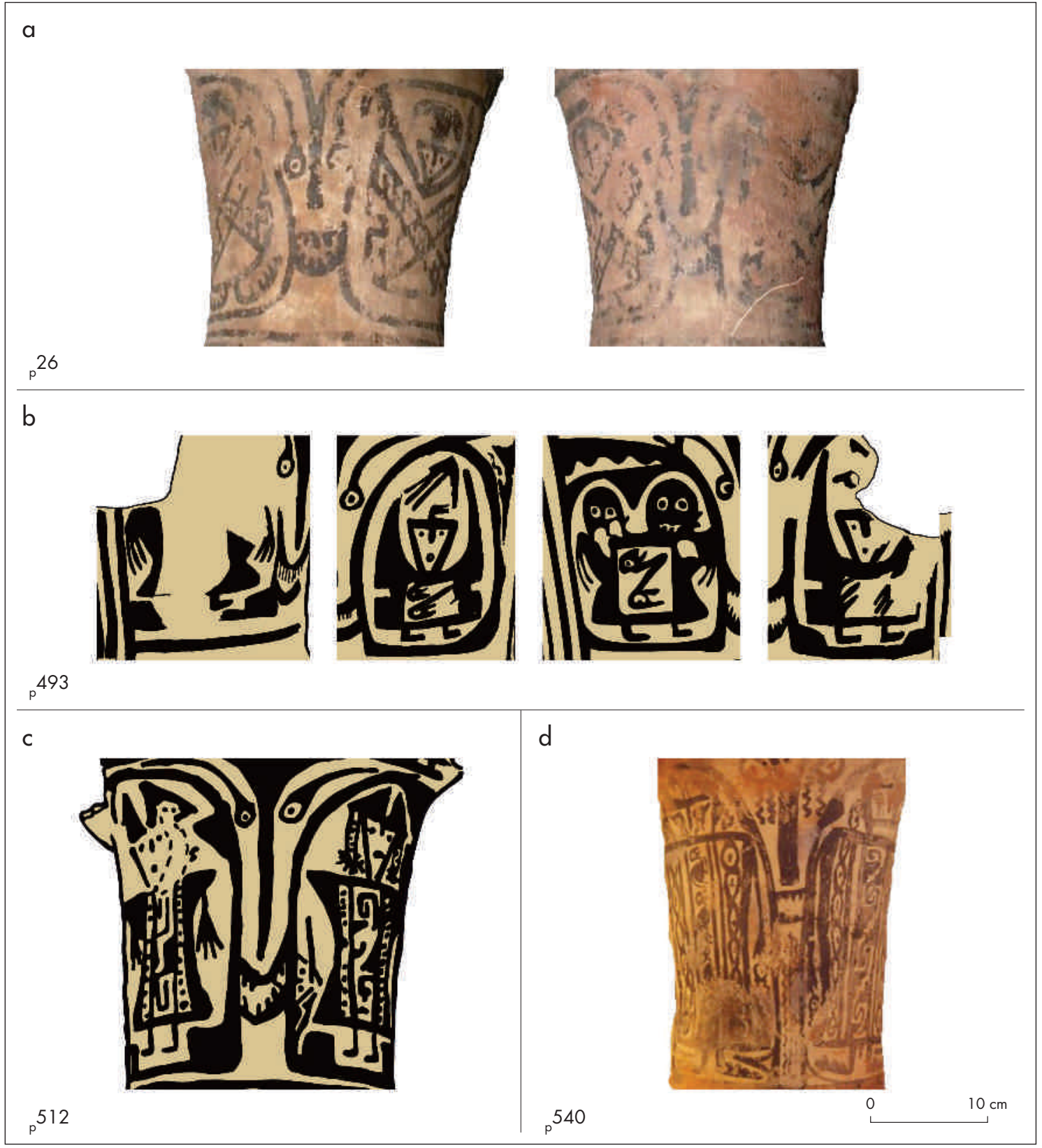

Figura 13: a) iconografía del cuello de 26 ; b) detalles de las representaciones en el cuello de 4 493; c) detalles de las representaciones en el cuello de $512 ; \mathrm{d}$ ) detalles de las representaciones en el cuello de 540 . Figure 13: $a$ ) iconography on the neck of ${ }_{p}^{\mathrm{p}}$ 26; $\boldsymbol{b}$ ) details of representations on the neck of $493 ; c)$ details of representations on the neck of $512 ; d$ ) details of representations on the neck of 540.

admite que para esta "facie" bicolor, su postulada "correspondencia" de la urna con la persona de la madre del párvulo que se encuentra inhumado en la pieza "se ha roto" (Velandia 2005: 177, 185).

En su Iconografía funeraria en la cultura arqueológica de Santa María, Argentina (2005), Velandia propuso hablar de atavíos en lugar de vestimenta u atuendos de los personajes antropomorfos, a los fines de incluir a "los adornos o arreglos de cabeza y los tatuajes o pintura facial. $\mathrm{Y}$ en el caso de los guerreros, también la parafernalia de las armas y escudos" (Velandia 2005: 185). El autor volvió sobre el caso de la pieza de la figura 8.a donde 


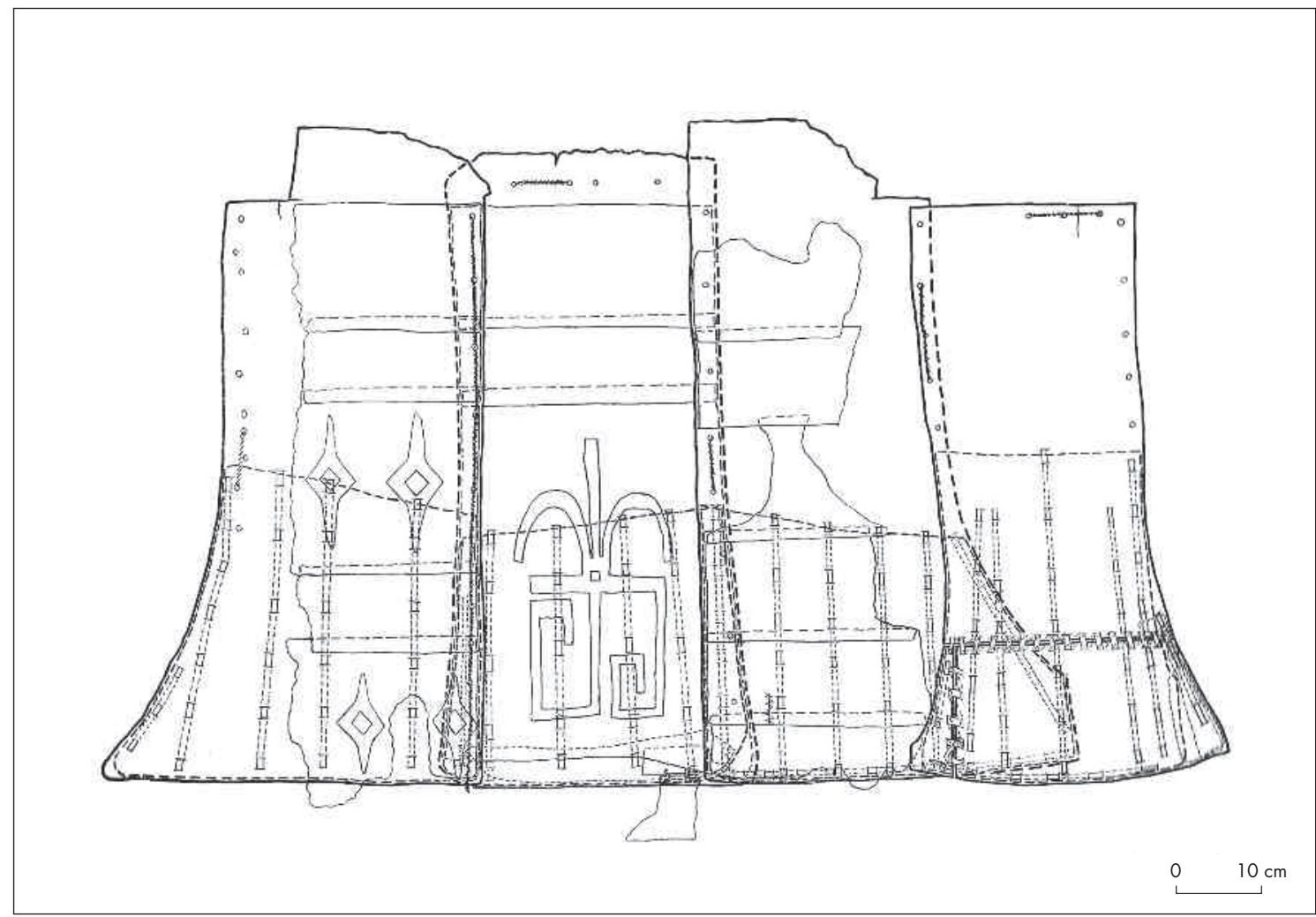

Figura 14. Coraza de cuero del río Loa (modificado de Rydén 1944: fig. 65). Figure 14. Leather breastplate from the Loa River (modified from Rydén 1944: fig. 65).

en una de las mejillas, el personaje antropomorfo vestido con túnica en forma de clepsidra, o reloj de arena, sostiene una cabeza trofeo boca abajo. En la vestimenta de este personaje, así también como en el escudo del antropomorfo del reverso de la misma pieza, y en los atuendos de los personajes de las mejillas de 293 (fig. 11c), se representa la imagen de una serpiente. En el caso de los tres personajes con atuendos en forma de clepsidra de esta última pieza, se trata de cabezas dobles de serpiente que se disponen en una sucesión vertical. Lo mismo vale para los antropomorfos con escudos en las mejillas izquierdas del anverso y reverso de ${ }_{\mathrm{p}} 291$ (fig. 12a). Los otros dos antropomorfos presentan sobre sus escudos el mismo diseño en " $\mathrm{X}$ ", muy similares a los de ${ }_{\mathrm{p}}^{87,}{ }_{\mathrm{p}} 1461,{ }_{\mathrm{p}}^{289,}{ }_{\mathrm{p}} 765,{ }_{\mathrm{p}} 974 \mathrm{y}_{\mathrm{p}} 26$ (figs. 1, 3e, 7b, $9 c, 10$ y 13a).

Podemos apreciar la presencia del recurso de la diferencia sutil en 303 (fig. 12b, Velandia 2005: 181), en la cual los atuendos de los cuatro personajes son idénticos y exhiben el mismo motivo: una banda vertical que contiene en su interior una sucesión de motivos en forma de "V". Los ornamentos cefálicos son también idénticos excepto en un caso en el cual en lugar de un tumi con penachos en los extremos, el personaje lleva un objeto rectilíneo dispuesto horizontalmente sobre su cabeza.

En los personajes de ambas caras de 493 el motivo decorativo de la vestimenta se mantiene entre una y otra mejilla, más cambia la forma del atavío: túnica clepsidra en la izquierda y escudo con escotadura en la derecha (fig. 13b). Esta urna se suma al lote de las que cargan con una relevancia especial en virtud de los motivos que exhibe. Se trata nuevamente de una pieza en mal estado de conservación con un notable motivo pintado en una de las mejillas: el antropomorfo de la izquierda del anverso tiene dos cabezas sobre los hombros, con los mismos atributos de la evidente cabeza trofeo de p 578 (fig. 11b): negra, ojos con órbitas oculares como si estuvieran vacías, boca cosida. El único rasgo distinto con aquella es la posición, pues en el caso de 578 tanto en el anverso como en el reverso las cabezas cercenadas 


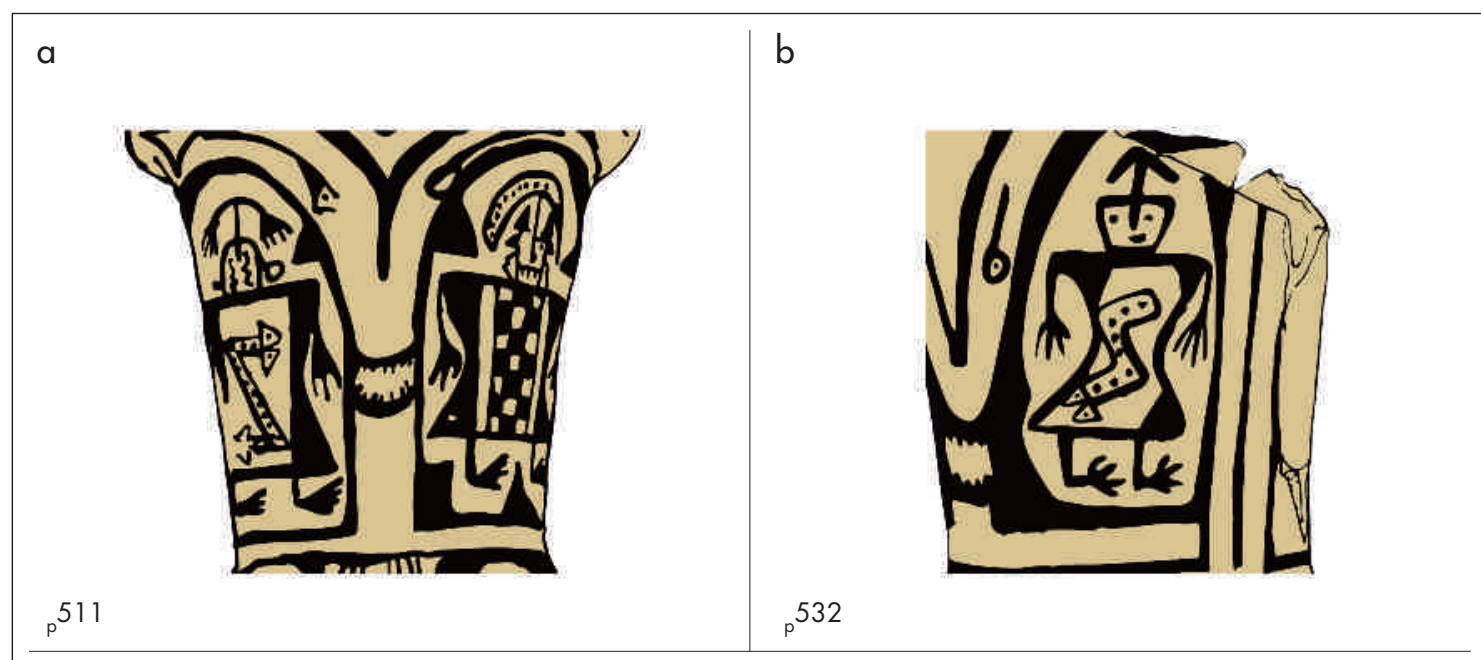

C
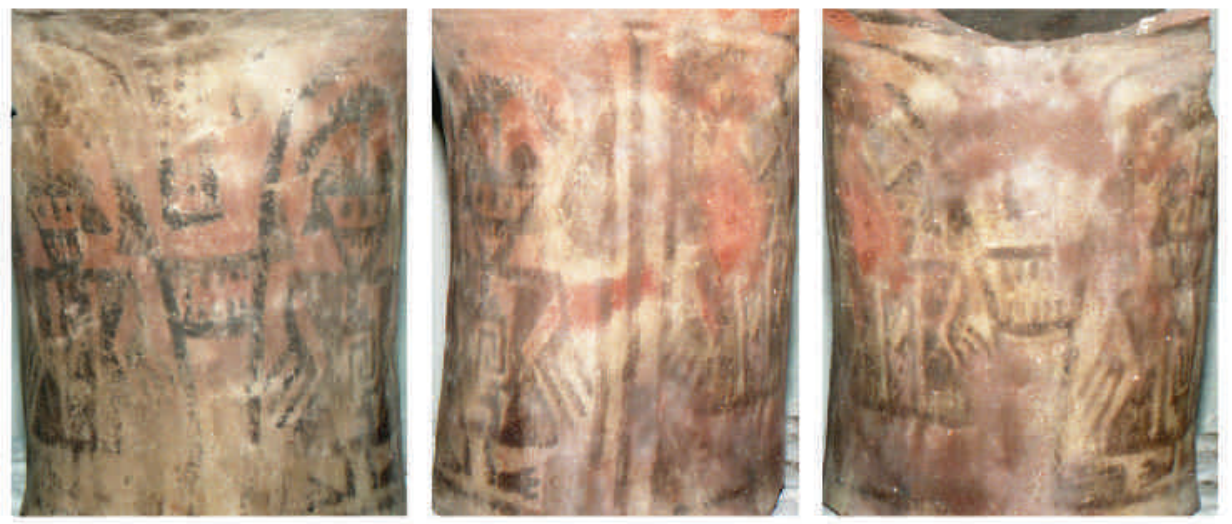

0

$10 \mathrm{~cm}$

Figura 15: a) detalles de las representaciones en el cuello de $511 ;$ b) detalle de una de las representaciones humanas en el cuello de 532 ; c) detalles de las representaciones en las mejillas de ${ }_{p} 83$. Figure 15: a) details of representations on the neck of $511 ; \boldsymbol{b}$ ) detail of human representations on the neck of $532 ; c$ ) details of representations on the cheeks of 83 .

aparecen sostenidas en posición invertida por parte de la figura de las largas cejas. Pero tan llamativo como la presencia de ambas cabezas sobre los hombros del personaje en 493 es el hecho de la aparente ausencia de la propia cabeza del antropomorfo. En el lugar donde debería estar la misma, se dispondría, en negativo, un motivo de doble arco, con las convexidades convergentes hacia el centro, similar al campo que delinean las cejas de la figura central de la misma pieza y de tantas otras similares.

En la coraza de cuero de caimán y mono procedente del río Loa, en el Norte de Chile (Rydén 1944), datada recientemente como correspondiente al período
Intermedio Tardío (Muñoz 2012), se encuentra grabada (fig. 14) una imagen antropomorfa con la cabeza figurada exactamente en el mismo modo que en la mejilla de 493: como dos arcos enfrentados que se disponen verticalmente por encima de la vestimenta (Rydén 1944: 108-111, Nielsen 2007: 23-25). En la coraza "física" recuperada en Chile queda así de manifiesto el juego de espejos o, mejor dicho, de "muñecas rusas" en el cual se inscriben las imágenes calchaquíes (Nastri 2007: 459, 2008: 22): el guerrero que portaba la coraza de cuero del río Loa llevaba así grabada en ésta una imagen en miniatura de un guerrero portando una coraza; la figura de las largas cejas de la urna ${ }_{\mathrm{p}} 493$ contiene en una de 
sus mejillas una miniatura de un personaje portando dos cabezas trofeo sobre sus hombros. Como el primer autor de este trabajo ha sugerido en otro lugar (Nastri 2008: 22), las "mejillas" de la figura de las largas cejas podrían corresponder en esta fase a los hombros de la misma, teniendo así las imágenes de las mejillas una posición idéntica a la de las cabezas cercenadas sobre el hombro del antropomorfo de la mejilla derecha del anverso de 1471 (fig. 3c).

En segundo lugar, y también vinculado al anterior concepto analogista de repetición metonímica a diferentes niveles de encastre (Descola 2011: 180), tanto la figura grabada en la coraza de cuero del río Loa como la imagen de la izquierda del anverso de 493 iluminan sobre la posible relación metonímica entre penachos curvos y rostros humanos. ${ }^{5}$ Además, el excepcional hallazgo de cuero también sugiere la posibilidad de que aquello que denominamos atuendo en forma de clepsidra, constituya en realidad una coraza y no una vestimenta textil. Rydén ha señalado el hecho de que la ampliación del diámetro de la coraza del río Loa en su porción inferior habría servido para facilitar la acción de correr por parte del combatiente (Rydén 1944: 111).

En 512 vemos nuevamente asociado a un personaje ataviado con prenda en forma de clepsidra, una cabeza cercenada (fig. 13c). Esta es sostenida por la mano derecha del personaje, pegada al cuerpo. La cabeza cercenada presenta los mismos rasgos que la del propio personaje: forma triangular, nariz indicada por una raya vertical, ojos indicados por puntos, boca dada por una mancha irregular; siendo aproximadamente la mitad del tamaño de esta última.

En 540 los personajes, ataviados con atuendos que no están ceñidos a la cintura, también tienen un objeto pendiente de sus manos (fig. 13d). Es de pequeño tamaño, forma circular y con unas extensiones lineales onduladas. En caso de tratarse de una cabeza cercenada, la misma tendría que estar reducida, práctica sobre la cual no hay antecedentes en la región. Podría corresponder en cambio a una cabeza de animal pequeño o de una representación de piedra y honda, sobre las cuales tampoco hay antecedentes reconocidos en la iconografía prehispánica del NOA. Lamentablemente no se cuenta con registro del reverso de la pieza que pudiera clarificar el referente del motivo.

p 511 y 532 (fig. 15 a y b) también exhiben personajes vestidos con atuendos en forma de clepsidra, pero en lugar de gorros o peinados, ostentan penachos de forma similar a los corrientes entre los antropomorfos con corazas. Por último, ${ }_{\mathrm{p}} 83$, también pintada con antropomorfos con túnicas, presenta similares penachos junto con gorros o peinados (fig. 15c). Finalizamos con esta pieza la compilación de registros gráficos dados a conocer entre 1879 y 2016 . A continuación, ensayaremos una síntesis cuantitativa del corpus documental reunido, a los fines de discutir distintas hipótesis respecto de cuestiones de significado en relación con los motivos antropomorfos.

\section{OBSERVACIONES GENERALES SOBRE LA MUESTRA COMPILADA}

De las 33 piezas identificadas en las publicaciones, 5 no han podido ser halladas aún en los museos. De las restantes 28 se ha ampliado el registro de 25 , extendiéndolo a ambas caras de las piezas, algo fundamental dado el carácter doble de la representación en las urnas santamarianas (Nastri 2014). El número total de 111 casos de antropomorfos documentados se distribuye de acuerdo con el siguiente detalle: 97 casos correspondientes a las 26 piezas de las cuales se cuenta con información completa, más otros 14 casos presentes en las 7 piezas con registros incompletos.

El número de 111 figuras antropomorfas documentadas en colecciones de museos y publicaciones es entonces un número mínimo. En el caso de que todas las mejillas hasta el momento no registradas también contaran con el motivo, se alcanzaría un número máximo de 125 figuras humanas de cuerpo completo, sin considerar la posibilidad de personajes en el sector interno del cuello, ni más de 4 en el exterior.

En la tabla 2 se presenta el detalle de la composición de la muestra, indicándose el repositorio museográfico en el cual se encuentra cada pieza, la colección a la que pertenece, la procedencia registrada y el tipo de antropomorfo que presenta en cada mejilla, entre otros datos.

Los dos casos en negrita corresponden a piezas consignadas en antiguas publicaciones que fueron ubicadas en colecciones de museos, pudiéndose de esta manera reconstruir la procedencia perdida o no consignada en los catálogos de las instituciones. ${ }^{6}$

Tomando en cuenta solo las 26 piezas de las cuales conocemos las representaciones de ambas caras, vemos que son absoluta mayoría los casos en los cuales se elige bien el atuendo en forma de clepsidra, o bien la coraza 


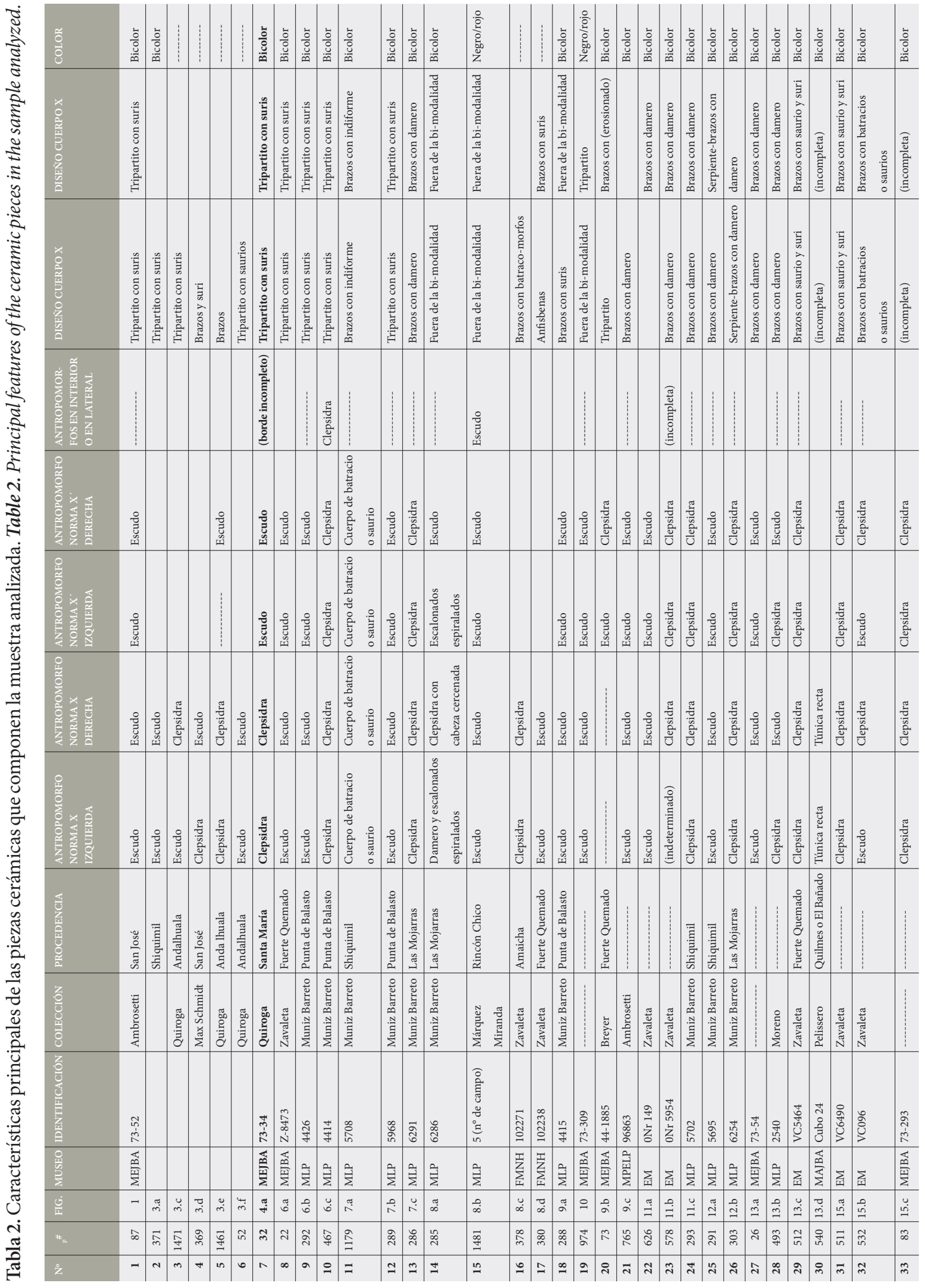


Tabla 3. Distribución de las piezas según contengan representaciones de corazas, de túnicas, o combinaciones de ambas. Table 3. Distribution of pieces according to representations of breastplates, tunics, or a combination of the two.

\begin{tabular}{|c|c|c|c|c|c|}
\hline & $\begin{array}{l}\text { TODOS LOS } \\
\text { ANTROPOMORFOS } \\
\text { CON ESCUDOS }\end{array}$ & $\begin{array}{l}\text { TODOS LOS } \\
\text { ANTROPOMORFOS } \\
\text { CON PRENDAS EN } \\
\text { FORMA DE CLEPSIDRA }\end{array}$ & $\begin{array}{l}\text { TODOS LOS } \\
\text { ANTROPOMORFOS } \\
\text { CON CUERPO } \\
\text { DE BATRACIO }\end{array}$ & $\begin{array}{l}\text { DIFERENCIA ENTRE } \\
\text { ANVERSO Y REVERSO } \\
\text { DE LA PIEZA }\end{array}$ & $\begin{array}{l}\text { DIFERENCIA } \\
\text { ENTRE MEJILLAS } \\
\text { DE UNA MISMA } \\
\text { CARA DE LA PIEZA }\end{array}$ \\
\hline 离 & $\begin{array}{l}\text { p } 87, \text { p22, p292, } \\
\text { p289, p291, p303, } \\
\text { p1481, p288, p974, } \\
\text { p765, p291, p26 }\end{array}$ & $\begin{array}{l}\text { p467, p286, p578? } \\
\text { (incompleta), p293, } \\
\text { p512, p511, p83 }\end{array}$ & p1179 & p1461, p32, p285 & p73, p493, p532 \\
\hline
\end{tabular}

para representar en todas las mejillas (anverso y reverso). Solo en tres casos se alternan ambos tipos entre anverso y reverso, y en otros dos la coexistencia de túnica con coraza se da en una misma cara de la urna (tabla 3). En referencia a esta última modalidad, resulta de utilidad considerar un caso de urna sobre la cual solo contamos con el registro de una cara $\left({ }_{\mathrm{p}} 1471\right)$, en la cual también coexisten ambos tipos de representación de la figura humana.

La variedad de tocados es más grande que la de atuendos y su clasificación se revela como un ejercicio difícil. Son muy populares los ornamentos cefálicos en forma de tumis, que en ocasiones se presentan superpuestos, a modo de sucesión. Lo mismo vale para los ornamentos en forma de cejas. Hay representaciones de gorros, de pelo y también casos que no presentan ningún adminículo por encima de la frente.

El caso de la coraza del río Loa alerta acerca de las similitudes entre las cejas de la figura de las largas cejas, los penachos en forma de cejas y el rostro de los personajes de las mejillas. El personaje grabado en la coraza presenta boca, más no así el resto de los atributos del rostro; en su lugar se dispone el penacho en forma de cejas. Algo similar puede decirse del personaje con las dos cabezas trofeo sobre los hombros de 4 493. En este caso, el posible rostro del personaje en forma de doble arco enfrentado se revela a través del efecto del uso de técnica negativa. Si bien el motivo de triángulo curvado pleno que genera el campo negativo en conjunción con los bordes de los cráneos trofeo es un elemento habitual de "relleno" al interior de los campos de diseño que contienen a los antropomorfos de las mejillas, nunca se dispone en posición sagital sobre la cabeza del antropomorfo, sino a los costados de la misma (p.e. 291, 512). De modo que es posible plantear que su uso en este caso o bien implica el reconocimiento de la ausencia de cabeza "propia" del antropomorfo, o bien -lo que nos inclinamos a pensar- una figuración por medio de técnica negativa, del penacho-largas cejas como metonimia de la cabeza del personaje.

Luego los otros casos de penachos en forma de cejas no reemplazan al rostro del personaje, sino que se disponen como tocados por encima de la cabeza, indistintamente de que se trate de figuras humanas con cuerpo en forma de clepsidra o con forma de coraza. El caso de 73 , en el cual se representa el penacho mas no así la cabeza (por más que haya "espacio" en la mejilla para la representación de la misma), sugiere también la posibilidad de un valor metonímico de los penachos respecto de las cabezas de los guerreros. Una alternativa es que representara la práctica de ocultar la cabeza bajo el escudo en el momento del combate.

Los motivos que interpretamos como cabezas cercenadas aparecen siempre vinculados a personajes con cuerpo en forma de clepsidra. Aquí nuevamente cabe considerar el hecho de que es posible que el uso de escudos impidiera visualizar cabezas portadas por el personaje. Pero la imagen de 512 ilustra que no es necesario que el personaje sostenga la cabeza como para poder representarla.

La variación de procedencias de la muestra es grande como para pretender reconocer tendencias por localidad. Pero según el detalle consignado en la tabla 4, la información disponible es suficiente como para establecer que las diferencias de atuendo no varían en consonancia con la procedencia geográfica. Esto es, en las pocas localidades de las cuales contamos con más de un caso, aparecen representadas ambos tipos de atuendos. Este hecho es coherente con la idea de que ambos tipos de representación del cuerpo de los personajes representan distintas funciones presentes en cada uno de los agrupamientos santamarianos, antes que ser distintivos de algunos de ellos. 
Tabla 4. Distribución geográfica de los tipos de atuendos de los personajes (en cantidad de piezas). Table 4. Geographic distribution of garments worn by figures, by type and quantity.

\begin{tabular}{|c|c|c|c|c|c|c|}
\hline & ESCUDOS & $\begin{array}{l}\text { PRENDAS EN } \\
\text { FORMA DE } \\
\text { CLEPSIDRA }\end{array}$ & $\begin{array}{l}\text { ESCUDOS + } \\
\text { CLEPSIDRAS }\end{array}$ & BATRACIOS & $\begin{array}{l}\text { TÚNICAS } \\
\text { RECTAS }\end{array}$ & $\begin{array}{l}\text { TOTAL } \\
\text { DE PIEZAS }\end{array}$ \\
\hline Amaicha & & 1 & & & & 1 \\
\hline Andalhuala & 1 & & 1 & & & 2 \\
\hline Fuerte Quemado & 1 & 1 & 1 & & & 3 \\
\hline Las Mojarras & & 1 & 1 & & & 2 \\
\hline Punta de Balasto & 3 & 1 & & & & 4 \\
\hline Quilmes & & & & & 1 & 1 \\
\hline Rincón Chico & 1 & & & & & 1 \\
\hline San José & 1 & & 1 & & & 2 \\
\hline Santa María & & & 1 & & & 1 \\
\hline Shiquimil & 2 & 1 & & 1 & & 4 \\
\hline Totales & 9 & 5 & 5 & 1 & 1 & 21 \\
\hline
\end{tabular}

En lo que respecta al recurso de la diferencia sutil (Nastri 2005-2006) -consistente en la sustracción, adición o cambio de orientación de un motivo o parte de este a los fines de romper la perfección de la simetría, sea con la otra mitad (sobre un eje vertical) de la cara de una pieza, o entre anverso y reverso de la misma-, cabe destacar que en el caso de las piezas bicolor repasadas siempre está presente. Casos donde queda especialmente de manifiesto el carácter intencional del recurso es cuando no se representan los pies en uno de los antropomorfos de las mejillas (fig. 13a). Como excepción cabe señalar el caso de la urna negro sobre rojo 1481 exhumada en el bajo de Rincón Chico. Esta presenta la particularidad de exhibir sus cinco personajes antropomorfos con idénticas características. Esto es, no se apela al recurso de la diferencia sutil. Marchegiani y otros observan que las urnas negro sobre rojo aparecen en abrumadora mayoría en el Valle de Yocavil, en contraste con el de Hualfín, a pesar de tratarse de piezas que integran elementos de los estilos Santa María y Belén, característicos respectivamente de cada uno de los valles referidos (Marchegiani et al. 2009). Tomando en consideración el hecho de que la dominación incaica fue sin duda plena en el Valle de
Hualfín, mientras que no habría sido completa en el Valle de Santa María (Lorandi 1991, Williams \& de Hoyos 2016: 55), tiene sentido la existencia en este último de piezas que cabe atribuir a población Belén movilizada, al tiempo que no se conoce hasta el momento un paralelo en cuanto a piezas que puedan atribuirse a población oriunda del Valle de Santa María fuera de éste.

Parece evidente que las piezas negro sobre rojo se inspiran en los personajes de las urnas santamarianas pero se diferencian a la vez de éstos, lo cual permite suponer que podrían haber sido realizados por artesanos no habituados a su confección. Por los caracteres enunciativos de las piezas, cabría pensar que podría tratarse de artesanos Belén movilizados por las huestes incaicas. También cabe pensar la posibilidad de que quienes pintaran la superficie de las vasijas fueran personas distintas de quienes fabricaban las pastas. Pero lo que a todas luces es evidente, es que el estilo de los antropomorfos de las urnas y del aríbalo negro sobre rojo es distinto del de las urnas santamarianas, principalmente en lo que respecta al cuerpo de los personajes.

En el caso de ${ }_{\mathrm{p}} 1481$, el motivo circular que oficia de decoración del torso de los personajes tiene un valor 

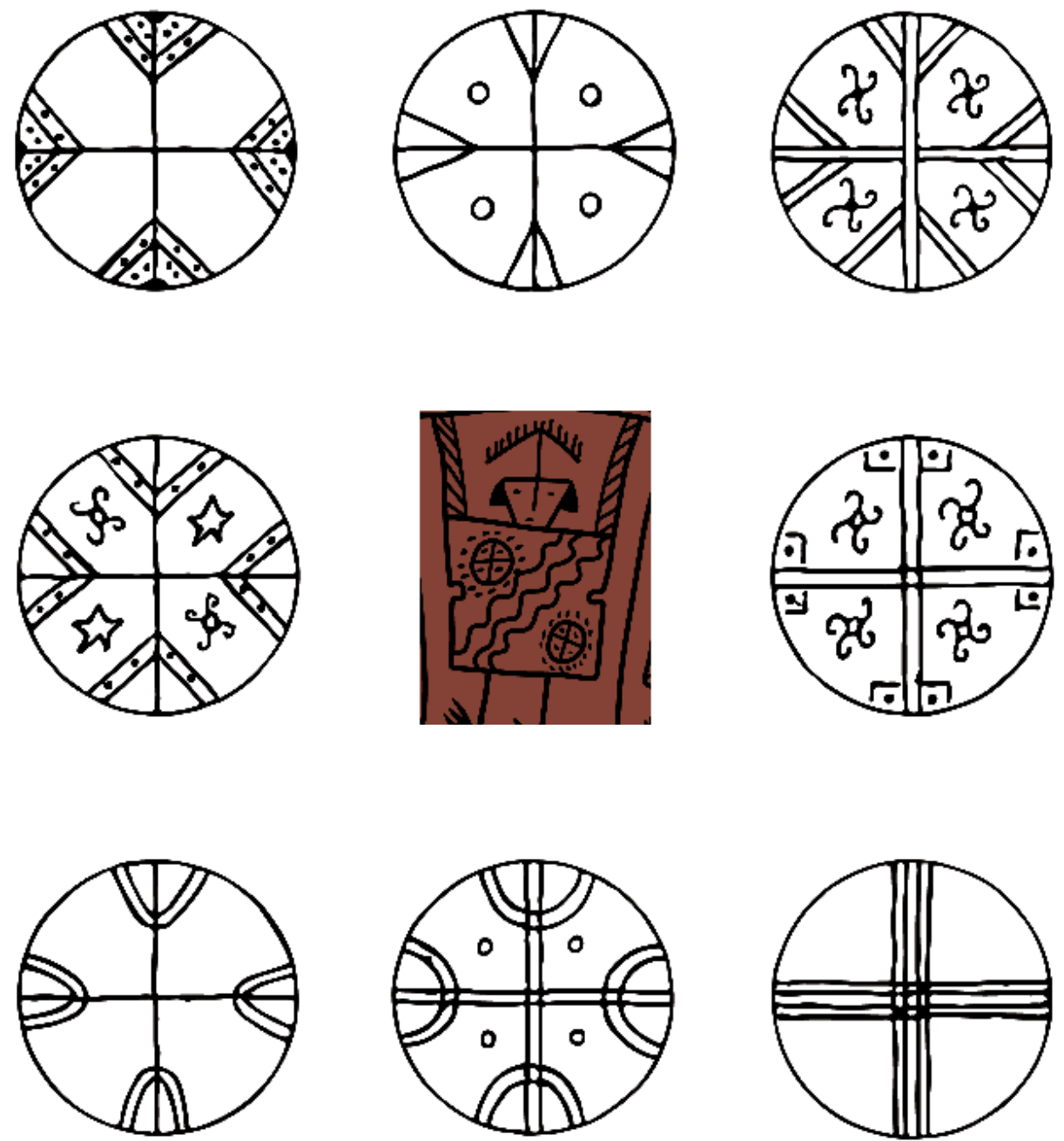

p 1481

Figura 16. Motivos circulares en 1481 en comparación con variedades de diseños pintados sobre parches de tambores chamánicos mapuches usados en la ceremonia ngillatum (modificadas de Grebe 1973). Figure 16. Circular motifs on 1481, compared to a variety of designs painted onto Mapuche shamanic drumheads used in the ngillatum ceremony (modified from Grebe 1973).

extra. Comparado con imágenes de los diseños pintados en el parche de los tambores mapuches usados en el ritual ngillatun, se aprecia que el motivo circular en cuestión tiene varias similitudes con algunas de las versiones publicadas del mismo (fig. 16). Grebe, quien obtuviera información etnográfica al respecto en Chile a fines de la década de 1960, señala al respecto que:
A pesar de que los dibujos del kultrún aparecen en múltiples variantes formales y colorísticas -de acuerdo a las distintas regiones, reducciones o machis a las cuales pertenezcan-, es posible afirmar que existen claros elementos formales constantes, los cuales se acentúan al máximo en instrumentos pertenecientes a machis del mismo rewe. Dichos elementos son la cruz doble o simple; los cuatro puntos o dibujos circulares distribuidos simétricamente en los espacios; las rayas angulares o semicirculares y puntos dobles o cuádruples con que termina cada brazo de la cruz. (Grebe 1973: 15). 
Observando el motivo de los escudos de los antropomorfos de 1481 a la luz de las variedades de diseños sobre el parche del kultrun ilustrados en la figura 16, se aprecia que el motivo incluido en la urna de Rincón Chico exhibe dos de los tres elementos formales constantes que enumera Grebe, al tiempo que incluye un cuarto -el perímetro exterior de puntos- ausente en el universo revisado por la etnógrafa chilena. Ahora examinando las variedades de diseños sobre los parches de tambores de la mencionada figura, también se aprecia que en la muestra de diseños mapuches seleccionadas por la autora solo el $60 \%$ de los casos presenta los tres elementos formales constantes. El resto solo presenta dos de esos elementos: la cruz y las rayas angulares o semicirculares y puntos dobles y cuádruples. De manera que cabe considerar la posibilidad lógica de una variedad de diseño que mantenga la cruz y los puntos y descarte las rayas angulares o semicirculares y puntos dobles y cuádruples. Tal es precisamente el caso del motivo incluido en los escutiformes de ${ }_{\mathrm{p}} 1481$, en el que se suma, por otra parte, un elemento no registrado en el registro de la autora: el perímetro exterior de puntos.

Por otra parte, en diseños interiores de pucos diaguitas-inka, también se representa una cruz similar con figuras incluidas en cada uno de los cuatro cuadrantes (González 2013) o con triángulos achurados en idéntica disposición y contorno que las rayas angulares de los extremos de las cruces de los diseños mapuches (Museo Chileno de Arte Precolombino 2014: 68). El análisis de este motivo a través de distintos contextos contemporáneos de los Andes meridionales amerita un estudio específico. A los efectos del presente, la mención basta para señalar que el hecho de la presencia en Yocavil durante tiempos incaicos, de motivos con notorias similitudes con otros propios de contextos contemporáneos de otros lugares del Collasuyu o incluso más allá de este, es comprensible a la luz de las conocidas prácticas imperiales de movilización de poblaciones locales (Lorandi 1991, Williams 2004). La consideración del posible carácter foráneo del motivo en cuestión, remite en principio a la misma pregunta en relación con el contenido temático de las representaciones humanas de cuerpo completo de las mejillas de las urnas que en el caso de las piezas negro sobre blanco: ¿los antropomorfos representan a personajes del propio grupo o de otro? Pero en el caso que fueran representaciones de personajes pertenecientes a grupos distintos al de los productores de los motivos, aún restaría determinar si se trata de referentes extra calchaquíes, extra Rincón Chico o bien propios de la misma unidad social de la cual formaba parte la población de este asentamiento.

Tanto en el caso particular de ${ }_{\mathrm{p}} 1481$, como en el resto de las urnas con antropomorfos, la elucidación del vínculo de productores y consumidores del discurso visual de las piezas con las imágenes de personajes contenidas en éstas, así también como la comprensión de la relación entre dichas representaciones y la figura de las largas cejas, constituyen aspectos clave a los fines del avance del conocimiento de las prácticas sociales vigentes durante los tiempos tardíos en el valle de Santa María. Dicha comprensión requiere de un conocimiento en detalle de cada uno de los términos de la relación. En esta oportunidad, el foco se colocó en el primer tipo de representaciones, sobre la cual existe además un extenso corpus hasta el momento inédito, que será objeto de la segunda parte del presente estudio.

\section{CONCLUSIONES}

Se ha repasado la publicación de datos parciales de 33 urnas santamarianas con representaciones humanas pintadas en sus mejillas desde el año 1879 hasta la actualidad. A partir de nuevas visitas a los museos de $\mathrm{La}$ Plata, Etnográfico de la Universidad de Buenos Aires y Prehistórico y Etnográfico de Roma, se completó la documentación fotográfica de normas faltantes de las piezas, así también como se registraron datos ausentes en las publicaciones, tales como números de inventario, procedencias, medidas, color Munsell, características morfológicas y diseños del interior de las piezas. Además, se incorporó información inédita de los relevamientos efectuados oportunamente en el Museo Etnológico de Berlín (Nastri 1999).

Se efectuó una primera clasificación de los motivos atendiendo a la forma del cuerpo, producto a su vez del tipo de atuendo o vestimenta usado por el personaje representado. A partir de la cuantificación de los casos entre anverso y reverso de las piezas y entre mejillas izquierdas y derechas, se advirtió que son pocos los casos en los que personajes con distinto tipo de vestimenta coexisten en una misma cara o en una misma pieza. Por otra parte, se observó una correspondencia entre cierto tipo de ornamentos cefálicos y los tipos de vestimenta del personaje. Los casos en que un lugar de procedencia cuenta con dos o más ejemplares en la muestra, han 
demostrado que no existió una distribución geográfica diferencial de los tipos de atavío de los personajes, lo cual es coherente con el hecho de la coexistencia en algunas piezas, de ambos tipos de atuendos. El hecho de que las representaciones sacrificiales se asocien exclusivamente a personajes con atuendos en forma de reloj de arena, podría ser indicativo de la representación de una función social distinta a la de los personajes ataviados con escudos. El examen en detalle de los pocos hallazgos de prendas de vestir y de defensa para la guerra usadas en el ámbito surandino durante los tiempos tardíos puede contribuir a la comprensión más profunda de los referentes iconográficos del arte santamariano.

La comparación de las imágenes de personajes de las mejillas de las urnas santamarianas variedad Yocavil, con las de piezas Belén-Santa María a Inca provincial sugiere que las segundas (muy escasas) se habrían inspirado en las primeras (mucho más numerosas). De esta manera, los personajes humanos de cuerpo completo, que en la imaginería propiamente cuzqueña son de época post-conquista, habrían sido incorporadas en tiempos precolombinos en piezas elaboradas por población no originaria del valle, en el contexto del sistema económico imperial. La identificación de un motivo de probable origen foráneo en el escudo portado por uno de los personajes, por otra parte, constituye un elemento de relevancia a la hora de considerar cuál habría sido el significado de las figuras en el contexto de la vasija. Esto es: la relación de los mismos con la figura de las largas cejas que constituye el leit motiv principal de las piezas.

Agradecimientos A Daniel Rampa y Leandro Palacios por su colaboración en el relevamiento de piezas del Museo Etnográfico. A Victoria Coll Moritán por la confección del mapa preliminar. A Carolina Aguilar, Selene Arislur, Cecilia Gentile y Jimena Ramón, por su colaboración en los relevamientos de piezas en el Museo de La Plata. A los directores del Museo Etnográfico de la UBA -Dra. Myriam Tarragó - y de la División Arqueología del Museo de La Plata -Dr. Rodolfo Raffino ( $\dagger$ ), Dra. Laura Miotti y Dr. Mariano Bonomo -, por permitir nuestro trabajo con las colecciones. Al personal de los depósitos de los siguientes museos donde se registraron las piezas que son objeto de estudio en el presente trabajo: Museo de La Plata (Dra. Ana Igareta, Lic. Jorgelina Collazo, Lic. Romina Giambelluca y Lic. Julieta Pellizari, del depósito 25; Sr. Jorge Kraidelberg (†) y Prof. Gabriel Alarcón, del depósito 5); Museo Etnográfico de la uba (Gabriela Amiratti, Prof. Silvia Manuale, Dra. Marina Marchegiani ( $\dagger$ ) y Lic. Alejandra Reynoso); Museo Prehistórico y Etnográfico de Roma (Dra. Donatella Saviola); Museo Etnológico de Berlín (Dra. Manuela Fischer).

\section{NOTAS}

${ }^{1}$ La base de datos de recipientes cerámicos del Período Intermedio Tardío completos o en fragmentos que superan el 20\% del volumen estimado de la pieza desarrollada por el primer autor, incluye a la fecha un total de 1483 registros, de los cuales un $76 \%$ corresponde a urnas funerarias.

${ }^{2}$ Los autores consignan la pieza como procedente de "Santa María", mas en el catálogo del Museo Etnográfico de la UBA figura como extraída por Manuel Zavaleta de la localidad de Fuerte Quemado.

${ }^{3}$ A la cual cabría describir como dualismo en perpetuo desequilibrio (Lévi Strauss 1992: 301).

${ }^{4}$ Cabe destacar la inclusión en el grupo de la fase $\mathrm{v}$ de p1481, del tipo negro sobre rojo o Belén-Santa María.

${ }^{5} \mathrm{Y}$ no se puede descartar que lo mismo valga para la imagen de la derecha del anverso de 73 (fig. 9b).

${ }^{6}$ En el caso de ${ }_{\mathrm{p}}^{22}$, se corrigió la procedencia publicada a partir de la información obtenida en el catálogo del Museo Etnográfico de la UBA.

${ }^{7}$ Velandia consigna erróneamente el número de catálogo de p289 como "5668" (Velandia 2005: 179).

\section{REFERENCIAS}

Ambrosetti, J. B. 1898. Notas de arqueología calchaquí. Boletín del Instituto Geográfico Argentino 19: 162-187.

Ambrosetti, J. B. 1899. Notas de arqueología calchaquí. Boletín del Instituto Geográfico Argentino 20: 162-187. 253-302.

Ambrosetti, J. B. 1902. El sepulcro de "La Paya" recientemente descubierto en los Valles Calchaquíes (Provincia de Salta). Anales del Museo Nacional de Buenos Aires, Tomo VIII (Ser. 3a, t. I): 119-148

Ameghino, F. 1881. La antigüedad del hombre en el Plata, Volumen 1. París-Buenos Aires: Masson.

Bruch, C. 1911. Arqueología de las provincias de Tucumán y Catamarca. Revista del Museo de la Plata 19.

Calderari, M. \& Williams, V. 1991. Re-evaluación de los estilos cerámicos incaicos en el Noroeste Argentino. Comechingonia 9 (II): 75-96.

Descola, P. 2011. La Fabrique des images. Visions du monde et formes de la représentation. París: Somogy.

GonzÁlez, A. R. 1977. Arte precolombino de la Argentina. Introducción a su historia cultural. Buenos Aires: Filmediciones Valero.

González, P. 2013. Arte y cultura diaguita chilena: simetría, simbolismo e identidad. Santiago: Ucayali.

Grebe, M. 1973. El kultrún mapuche: un microcosmo simbólico. Revista Musical Chilena 27: 3-42.

LAfone Quevedo, S. 1908. Tipos de alfarería en la región diaguita-calchaquí. Revista del Museo de La Plata 15: 295-396.

LeVi STRAuss, C. 1992. Historia de lince. Barcelona: Anagrama. 
LiberANi, I. \& HeRnÁNDEZ, R. 1951. Excursión arqueológica en los valles de Santa María, Catamarca. 1877. Tucumán: Universidad Nacional de Tucumán.

LorANDi, A. M. 1991. Evidencias en torno a los mitmaqkuna incaicos en el NO argentino. Anthropologica 9: 213-231.

Marchegiani, M., Palamarczuk, V. \& Reynoso, A. 2009. Las urnas negro sobre rojo tardías de Yocavil, Noroeste Argentino. Reflexiones en torno al estilo. Boletín del Museo Chileno de Arte Precolombino 14 (1): 69-98.

Márquez Miranda, F. 1939. La antigua provincia de los diaguitas. En Historia de la Nación Argentina, Volumen I, Junta Nacional de Historia y Numismática, Ed., pp. 273-327. Buenos Aires.

Márquez Miranda, F. 1946. Los diaguitas. Inventario patrimonial arqueológico y paleo etnográfico. Universidad Nacional de La Plata, La Plata.

Márquez Miranda, F. \& Cigliano, E. 1957-1959. Ensayo de una clasificación tipológica cronológica de la cerámica santamariana. Notas del Museo de La Plata 19 (63 Antropología): 1-27.

Márquez Miranda, F. \& Cigliano, E. 1961. Un nuevo antigal catamarqueño: el yacimiento arqueológico de Rincón Chico (Depto. de Santa María, Prov. de Catamarca). Revista del Museo de La Plata (Nueva Serie) v (Antropología 27): 179-192.

MuÑoz, A. 2012. From curiosa to world culture. A history of the Latin American collections at the Museum of World Culture in Sweden. Gotarc. Series B, No. 58. University of Gothenburg, Gotemburgo.

Museo Chileno de Arte Precolombino. 2014. Chile antes de Chile. Santiago.

NASTRI, J. 1999. El estilo cerámico santamariano de los Andes del sur (Noroeste Argentino, siglos XI a XVI). BaesslerArchiv 47: 361-396.

NASTRI, J. 2003. Aproximaciones al espacio calchaquí. Anales 6: 99-125.

NAstRI, J. 2005-2006. El simbolismo en la cerámica de las sociedades tardías de los Valles Calchaquíes (siglos XI a XVII). Arqueología 13: 253-261.

NAStri, J. 2007. La lógica del sacrificio en la iconografía calchaquí. Pacarina: 457-462.

NASTRI, J. 2008. La figura de las largas cejas de la iconografía santamariana. Chamanismo, sacrificio y cosmovisión calchaquí. Boletín del Museo Chileno de Arte Precolombino 13 (1): 9-34.

NASTRI, J. 2009. La noción de transformación en arqueología antropológica y la interpretación del simbolismo santamariano. En Perspectivas actuales en arqueología argentina, R. Barberena, K. Borrazzo \& L. Borrero, Eds., pp. 91-120. Buenos Aires: IMICIHU.

NAstRI, J. 2014. Territorios de significación. La variación estilística calchaquí y sus implicancias sociales. En Las Tierras altas del área centro sur andina entre el 1000 y el 1600 DC TANOA II, Albeck, M.E., Ruiz, M. \& B. Cremonte, Eds., pp. 89-120. San Salvador de Jujuy: unju.
Nastri, J. \& Coll Moritan, V. 2009. Variabilidad del estilo santamariano. En Problemáticas de la arqueología contemporánea. Tomo III, Austral, A \& M. Tamagnini, Eds., pp. 729-734. Río Cuarto: Universidad Nacional de Río Cuarto.

NAstri, J. \& Vietri, L. 2004. I Calchaquí, cento anni dopo. Note sulla collezione Ambrosetti del Museo Pigorini. Bulletino di Paletnologia Italiana 95: 355-377.

NielsEn, A. 2007. Armas significantes: tramas culturales, guerra y cambio social en el sur andino prehispánico. Boletín del Museo Chileno de Arte Precolombino 12 (1): 9-41.

Outes, F. 1907. Alfarerías del Noroeste Argentino. Anales del museo de La Plata 1: 1-52.

Perrotta, E. B. \& Podestá, C. 1978. Contribution to the San José and Santa María Cultures, Northwest Argentina. En Advances in Andean archaeology, David Browman, Ed., pp. 525-552. Chicago: Mouton.

Podestá, C. \& De Perrotta, E. B. 1973. Relaciones entre culturas del Noroeste Argentino. San José y Santa María. Antiqüitas 17: 6-15.

Quiroga, A. 1901. La cruz en América. Buenos Aires: Imprenta T. Litografía.

Quiroga, A. 1992 [1897]. Folclore calchaquí. Buenos Aires: TEA.

RYDÉN, S. 1944. Contributions to the archaeology of the Rio Loa Region. Gotemburgo: Elanders Boktryckeri Aktiebolag.

TARragó, M., GonzÁLEZ, L. \& NASTRI, J. 1997. Las interacciones prehispánicas a través del estilo: el caso de la iconografía santamariana. Estudios Atacameños 14: 223-242.

Velandia, C. A. 2005. Iconografía funeraria en la cultura arqueológica de Santa María - Argentina. INCUAPA, Serie Monográfica $\mathrm{N}^{\circ}$ 4. Ibagué: Universidad Nacional del Centro de la Provincia de Buenos Aires. Universidad del Tolima.

WAgner, D. \& WAgner, E. 1934. La civilización ChacoSantiagueña y sus correlaciones con las del Viejo y Nuevo Mundo, Tomo I. Buenos Aires: Compañía Impresora Argentina, S.A.

Weber, R. 1978. A seriation of the late prehistoric Santa Maria culture of Northwestern Argentina. Fieldiana Anthropology 68: 49-98.

Weber, R. 1981. An analysis of Santa Maria urn painting and its cultural implications. Fieldiana Anthropology 2: 1-32.

Williams, V. 2004. Poder estatal y cultura material en el Kollasuyu. Boletín de Arqueología PUCP 8: 209-245.

Williams, V. \& DE Hoyos, M. 2016. Trascendiendo materialidades. Aproximaciones interdisciplinarias y estrategias de investigación del pasado prehispánico en el Noroeste Argentino. En Disciplinas sin fronteras. Homenaje a Ana María Lorandi, R. Boixadós \& C. Bunster, Eds., pp. 49-96. Buenos Aires: Facultad de Filosofía y Letras. 